\title{
Pulsed Laser Welding Applied to Metallic Materials-A Material Approach
}

\author{
Mariane Chludzinski *, Rafael Eugenio dos Santos, Cristina Churiaque (D, Marta Ortega-Iguña \\ and Jose Maria Sánchez-Amaya
}

check for

updates

Citation: Chludzinski, M.; dos

Santos, R.E.; Churiaque, C.;

Ortega-Iguña, M.; Sánchez-Amaya,

J.M. Pulsed Laser Welding Applied to

Metallic Materials-A Material

Approach. Metals 2021, 11, 640.

https://doi.org/10.3390/

met11040640

Academic Editors: Antonio Riveiro and Wei Zhou

Received: 26 February 2021

Accepted: 10 April 2021

Published: 14 April 2021

Publisher's Note: MDPI stays neutral with regard to jurisdictional claims in published maps and institutional affiliations.

Copyright: (c) 2021 by the authors. Licensee MDPI, Basel, Switzerland. This article is an open access article distributed under the terms and conditions of the Creative Commons Attribution (CC BY) license (https:// creativecommons.org/licenses/by/ $4.0 /)$.
Department of Materials Science and Metallurgical Engineering and Inorganic Chemistry, LABCYP, Faculty of Engineering, University of Cádiz, Av. Universidad de Cádiz 10, E-11519 Puerto Real (Cádiz), Spain; rafaeleugeniodossantos@gmail.com (R.E.d.S.); cristina.churiaque@uca.es (C.C.); marta.ortega@uca.es (M.O.-I.); josemaria.sanchez@uca.es (J.M.S.-A.)

* Correspondence: mariane.chludzinski@uca.es; Tel.: +34-956-483153

\begin{abstract}
Joining metallic alloys can be an intricate task, being necessary to take into account the material characteristics and the application in order to select the appropriate welding process. Among the variety of welding methods, pulsed laser technology is being successfully used in the industrial sector due to its beneficial aspects, for which most of them are related to the energy involved. Since the laser beam is focused in a concentrated area, a narrow and precise weld bead is created, with a reduced heat affected zone. This characteristic stands out for thinner material applications. As a non-contact process, the technique delivers flexibility and precision with high joining quality. In this sense, the present review addresses the most representative investigations developed in this welding process. A summary of these technological achievements in metallic metals, including steel, titanium, aluminium, and superalloys, is reported. Special attention is paid to the microstructural formation in the weld zone. Particular emphasis is given to the mechanical behaviour of the joints reported in terms of microhardness and strength performance. The main purpose of this work was to provide an overview of the results obtained with pulsed laser welding technology in diverse materials, including similar and dissimilar joints. In addition, outlook and remarks are addressed regarding the process characteristics and the state of knowledge.
\end{abstract}

Keywords: pulsed laser welding; metallic materials; aluminium; titanium; steel; superalloys; microstructure; hardness; mechanical properties

\section{Introduction \\ 1.1. Description}

Laser technology is being widely used as a joining technique in several materials, including metallic alloys. As a non-contact process, the laser source generates a small spot beam focused on top of the surfaces, producing high energy densities for melting and mixing the base materials into a welding pool. After a rapid laser beam exposition, the fast solidification creates the weld seam [1-3]. In this process, the joints are autogenously generated without additional material. However, in some cases a filler metal or interlayer material is commonly used in dissimilar welds as a strategy for diminishing thermal and physical properties differences [4,5].

A remarkable advantage of this technology is the capacity to achieve high irradiance, which concentrates laser beam with low divergence, generating joints with minimal mechanical stress and low distortion [2,6-8]. Moreover, another important factor related to the focused energy density is its singular joining efficiency, higher than the arc welding processes [9]. In terms of industrial applications, this technique offers flexibility and precision besides the excellent joint quality, aligned with the fast welding speed, leading to a high production rate $[10,11]$. In addition, the possibility to join dissimilar materials with high quality amplifies its range of implementation [12-14]. Similar to other welding technologies, 
laser technology has some limitations and disadvantages, which can be related to the high costs of equipment and its restricted requirements of operation and training, besides the precise alignment of the laser beam and the contacted faces of materials [10]. Furthermore, the thermal and physical characteristics of the materials can affect the weldability when materials with high thermal conductivity or high reflectivity are involved [15].

The operability of the laser process can be worked in two main distinguished modes, continuous and pulsed. In the continuous modes, the incidence of the laser beam on the material is uninterrupted, the laser irradiation is constant during the time and forms a continuous weld bead. Meanwhile, in the pulsed, the intermittent laser wave has a predetermined duration (milliseconds or less), which repeats in a specific frequency, creating a sequence of spots. Furthermore, the periodic high energy density of pulsed mode promotes a single point of material heating, reaching the fusion state and creating a weld pool, followed by the rapid cooling rate during the solidification stage. Therefore, the series of pulsed fusion zones overlapped generates the weld seam [15-18]. Even with the high peak power of each pulse, the intermittent configuration conducts a low average power $[11,19,20]$. Moreover, the behaviour of lower heat input and sharply high energy focused provokes minor disturbances in the materials, developing welding seams with condensed melting and affected areas [9,21]. Another important aspect is the penetration efficiency, which is higher in pulse than continuous mode under similar conditions [19,22]. The concentrated heat input and the quality issues aforementioned have given special attention to the use of this pulsed welding for joining thin materials [15-17].

Pulsed laser welding equipment usually involves $\mathrm{CO}_{2}, \mathrm{Nd}$ :YAG, or fibre sources $[18,23]$. Among them, Nd:YAG displays a flexible beam delivered with industrial units commercially available $[24,25]$. The majority of the pulsed laser investigations have been performed with this system, probably due to the higher production efficiency and ability to control welding parameters [26]. The main experimental parameters in pulsed laser welding are peak power, pulse time, spot size, welding speed, and the distance between consecutive pulses $[21,23,27,28]$.

The configuration of both the power density and welding speed and the laser beam interaction with the materials define the welding regime, which can be characterised as three modes: penetration or keyhole, conduction, and the most recent type-transition (Figure 1). The penetration mode requires the use of a high energy density (usually higher than $10^{6} \mathrm{~W} / \mathrm{cm}^{2}$, although this threshold reference value depends on the material) to reach a high evaporation rate, allowing the beam to enhance deep penetration inside the material and creating a vapour cavity. This phenomenon, also known as keyhole, produces a hole surrounded by melted material interfaced with the solid substrate. The vapour pressure within conserves the keyhole due to a complex combination of physical mechanisms of conductive and convective heat transfer, laser absorption, and hydrodynamic flow around the keyhole inside the melt pool. Then, this mode promotes weld seams deeper and thinner than in the conduction mode. However, the unstable mechanism of the keyhole can produce porosities as a consequence of the gas trapping during the weld pool solidification $[10,16,18,29,30]$. In contrast, conduction mode is more stable than the keyhole. It implies less energy density, with insignificant vaporisation of the material [31]. The generation of the melt pool is mainly controlled by the heat input and welding speed, in which the absorbed intensity is lower than $10^{6} \mathrm{~W} / \mathrm{cm}^{2}$ [16]. Meanwhile, the low penetration depth is the main disadvantage of this regime $[18,29]$.

The intermediate configuration has been identified as transition mode. Interestingly, this mode allows higher welding tolerances than the keyhole mode with deeper penetration than the conduction mode. Therefore, it complements the characteristics to develop a quality joint, maintaining the composition and welding properties similar to the base metal [32-35]. 


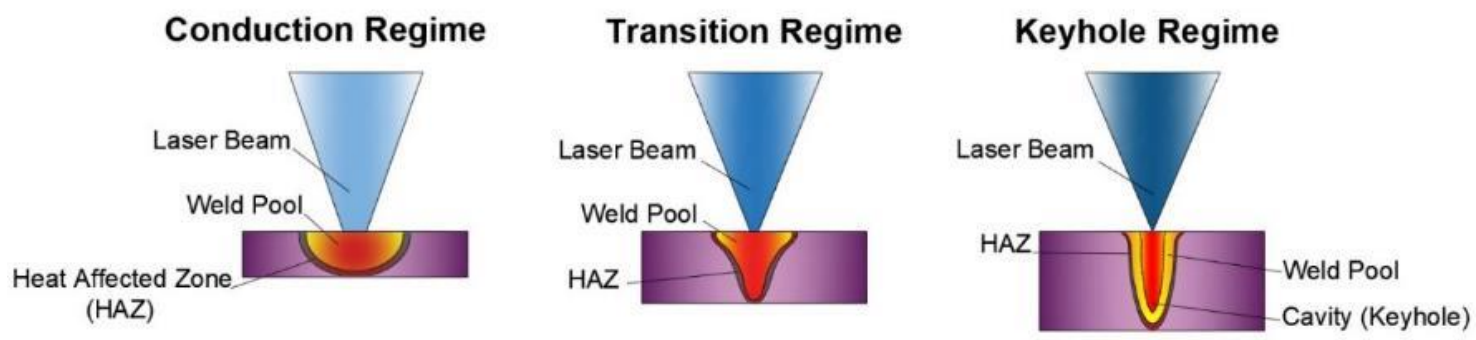

Figure 1. Different regimens of pulsed laser process. Adapted with permission from [36]. Copyright 2017 MDPI.

In all regimes, the optimisation of strategic factors enhances joint quality. Among these, the energy delivered to the materials is fundamental, and it depends on the input parameters as laser peak power, pulse time, spot diameter, welding speed, and pulses overlapping $[21,25,37,38]$.

Regarding the overlapping factor, in order to produce a superposition of consecutive pulses, the distance between two pulse centre points must be lower than the superficial melting diameter (Figure 2). In this case, the partial superposition interferes in the fusion zone (FZ) of the previous pulse, generating a continuous FZ of the weld seam $[21,39,40]$. Consequently, a high overlapped factor can be used to obtain a homogeneous weld bead. It will depend on the thickness of the materials and the welding parameters involved.

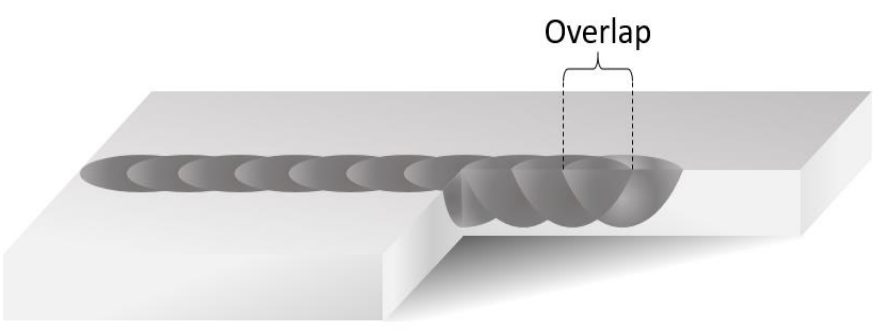

Figure 2. Overlapping schematically illustrated. Adapted with permission from [41]. Copyright 2014 Elsevier.

\subsection{Microstructural Evolution}

Microstructure evolution is a consequence of the arrangement of welding parameters, which designates the energy generated by the combination of laser beam power, peak power, welding speed, spot diameter, frequency, pulse overlap, and time [18,21]. According to this combination, the cooling rate and heat input define the behaviour of melting and solidification profiles. One pulse usually takes milliseconds, which indicates that this stage is indubitably fast, especially for the reduced volume of material implicated.

The main effect of pulse welding is to create a FZ located in the centre of the weld bead. The sharp and focused beam generated by a single pulse concentrates the energy, enhancing temperatures above the melting point. After that, the temperature decreases, and the material returns to the solid state. In this cooling process, grains start to grow into the welding pool perpendicular to the fusion boundary due to the high heat conduction developed in this direction. The subsequent laser pulse is displaced at a close distance from the previous pulse, repeating the same steps successively. If the distance between the two pulses is lower than an FZ radius, the volume of material affected will be overlapped, creating the weld seam. This overlapped volume is submitted to multiple expositions, undergoing melting and solidification processes repeatedly. In this sense, some investigations characterised the FZ in sub-regions, which are created by the successive rapid thermal cycles $[11,17,21,42]$. As illustrated in Figure 3, according to this division, one region corresponds to the material only subjected to a single pulse (Z1 of Figure 3), while the two following pulses affected the other zones. The Z2 was first exposed to pulse I, and subsequent pulse II affected it by the thermal gradient created. Meanwhile, Z3 was 
subjected to the superposition of pulses I and II. Due to the high temperatures, pulse I changed the microstructure of the $Z 1$ only once, while the subsequent pulses modified $\mathrm{Z} 2$ and $\mathrm{Z} 3$ twice. In the $\mathrm{Z} 2$, pulse II reheats the microstructure generated by the previous pulse without reaching the melting point for a second time. However, the temperature involved in $\mathrm{Z} 3$ was high enough to reach the melting point for the second time by pulse II. Altogether, all the thermal gradients generated in each zone are responsible for the formation of the microstructures of each zone, created by the high cooling rates during the solidification stage that varies with the local thermal cycles and the peak temperatures.

Another region created by the process is called the heat-affected zone (HAZ). Analogous to the other welding process, this region was exposed to temperatures below the melting point but high enough to change its characteristics. The HAZ created by laser usually has diminished dimensions compared to the fusion welding processes due to the focused heat input [15].

All zones develop specific microstructures associated with the material type, the concise chemical composition, and solidification conditions. Alloys with minimal differences in chemical elements can generate significant variation in microstructure and properties. Regarding the solidification condition, alteration in the solidification and cooling rates can also notably modify the microstructure. Even with the same composition, the thermal cycles experienced for each zone define the microstructures and properties. Generally, the solidification process is divided into nucleation and growth mechanisms. It can be developed as planar, cellular, cellular dendritic, columnar dendritic, equiaxed dendritic modes, and their combination, depending on the temperature gradient and the solidification rate, as shown in Figure 4. Among these modes, dendritic or cellular are the most common created in FZs. Planar growth occurs with a high temperature gradient or low solidification rate and their combination. In opposition, the equiaxed dendritic mode is generated when the temperature gradient is very shallow $[43,44]$. As the FZ boundary undergoes rapid cooling rates due to the fast heat conduction, the centre displays a lower solidification rate. Therefore, the region near the weld interface can be governed by planar and cellular growth, while the centre of FZ exhibits a dendritic growth [45].

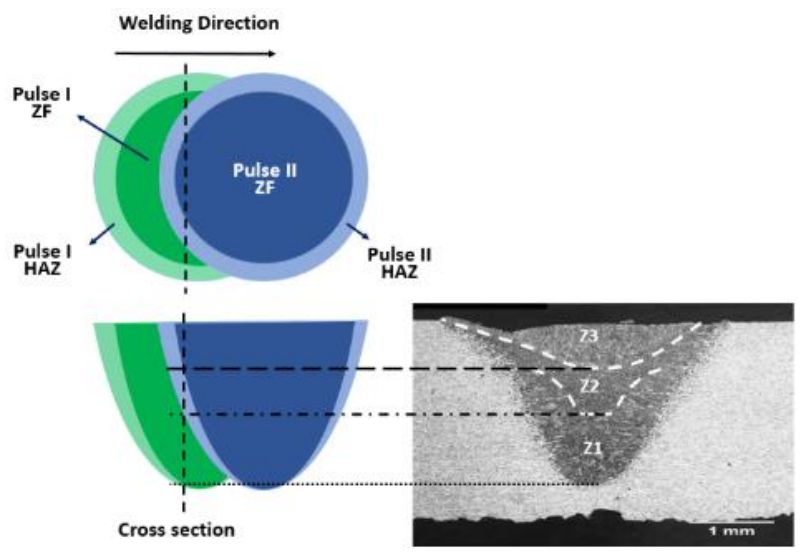

Figure 3. Schematic illustration of the pulse overlapping and its effect on the weld bead [21]. Copyright 2021 Elsevier.

For numerous engineering applications, joining two different materials is essential to achieve the necessary component characteristics. Nevertheless, dissimilar welding is a technological challenge since the materials exhibit different chemical compositions and mechanical properties. In this sense, besides the microstructure evolution, the characteristics of the materials involved are another important aspect to be considered. Since the materials have different physical and thermal properties, some properties significantly affect the interaction with the laser beam, influencing the performance of the process. For this reason, the melting temperatures, thermal expansions, heat capacities, and thermal conductivities could be considered during the selection of materials [46-50]. 


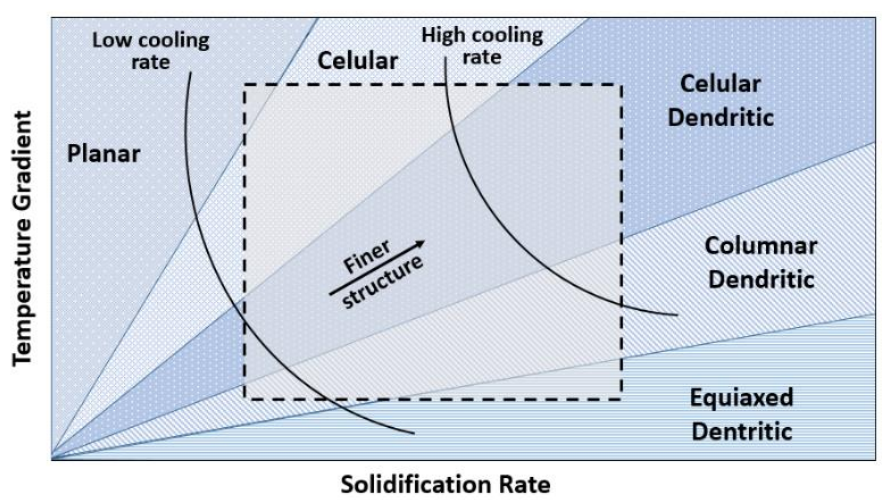

Figure 4. Schematic illustration of solidification growth. The internal square corresponds to typical weld morphology. Adapted with permission from [43]. Copyright 2015 John Wiley \& Sons, Inc.

\subsection{Industrial Applications}

Due to the abovementioned characteristics, the industrial sectors have adopted the pulsed laser technology as an alternative to conventional welding processes. The precise and controlled power generation supports a defined distribution of the heat in the material, resulting in a concentrated weld bead. This has expanded the use of this process in a wide range of applications, besides the low maintenance cost involved [24].

Some industrial processes require a combination of thin and complex components, especially in microelectronics and engineering devices. This scenario demands the precision and accuracy characteristics that the pulsed technology can provide. The high level of repeatability and reproducibility permits, for example, welding vehicle parts as airbag assemblies, ignition controls, batteries, and fuel injectors. Laser pulse welds are also found in the medical sector, such as implants, surgical tools, and orthodontic appliances [51], and in the mobile phones and solar cells electronic components. Other examples are found in the fabrication of jewellery and watches, as well as thermocouples, micro-turbines, motors, and gears $[18,23]$.

\subsection{Scientific Developments}

The benefits of pulsed laser welding have been demonstrated in the research, exploring its flexibility to replace the conventional methods and its applicability in the new designs and material combinations. The field of material and its application are vast in response to technological advancement. Regarding recognising the scientific studies direction that have been developed in terms of materials, the present review aimed to perform data analysis, gathering information on the basis of the articles published in Science Direct, Springer, and MDPI online platforms in the last 10 years. This analysis was based on investigations performed in the pulsed laser process applied to steels, followed by titanium, aluminium, and superalloys. Other research involves welding with different materials, such as magnesium, zirconium, and copper were also counted. The histogram compiled in Figure 5 shows the percentage distribution of the 207 works published since 2010; 81\% of them had the approach in similar alloys, whereas 19\% focused on dissimilar joints (Figure 6).

\subsection{Scope}

The pulsed laser application as a welding process has been investigated in several metallic alloys using different welding conditions, creating weld seams with distinguishing characteristics. In this sense, this review aimed to be the earliest study to combine the achievements related to metallurgical and mechanical properties of weldments made with steel, titanium, aluminium, and superalloys. The outcomes are focused on microstructure generated by the pulsed process, as well as hardness and strength performance in similar and dissimilar joints. This compilation focused on Nd:YAG laser since it is the principal source used for pulsed welding application. The readers will be able to visualise the 
microstructural modifications as well as the joints generated. A summary of the process characteristics can also be seen according to each material evaluated.

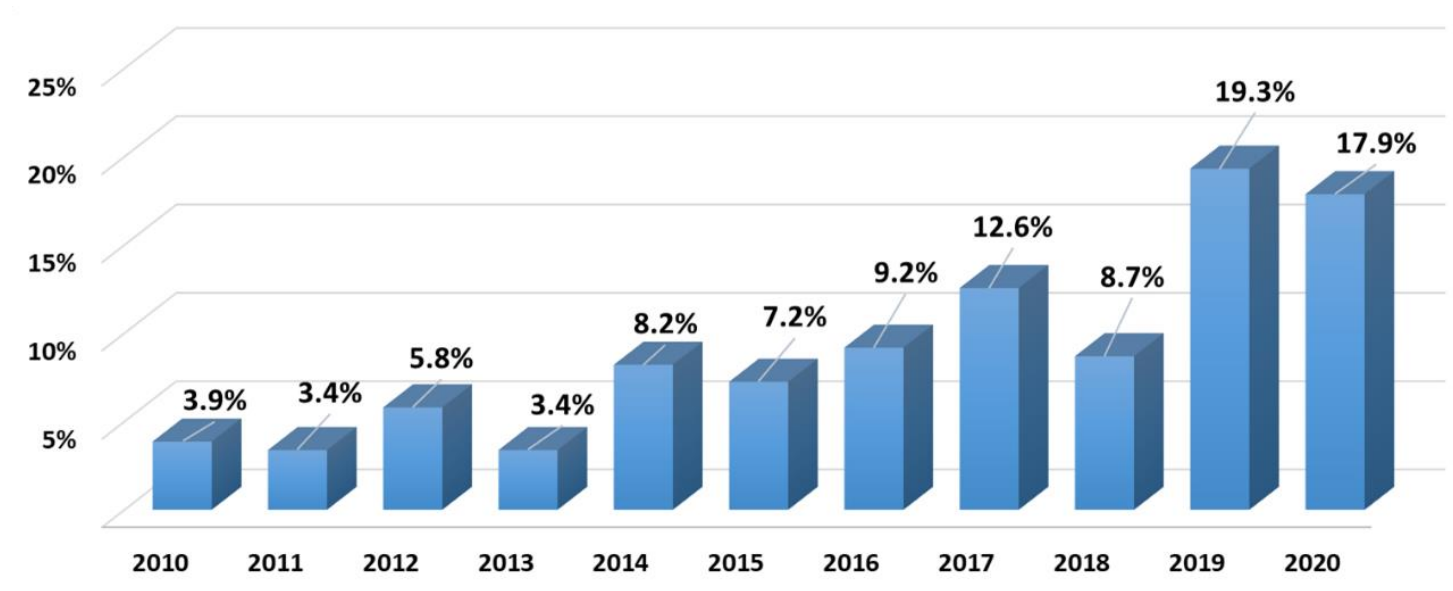

Figure 5. Number of published documents related to pulsed laser welding.

Similar Pulsed Laser Joints

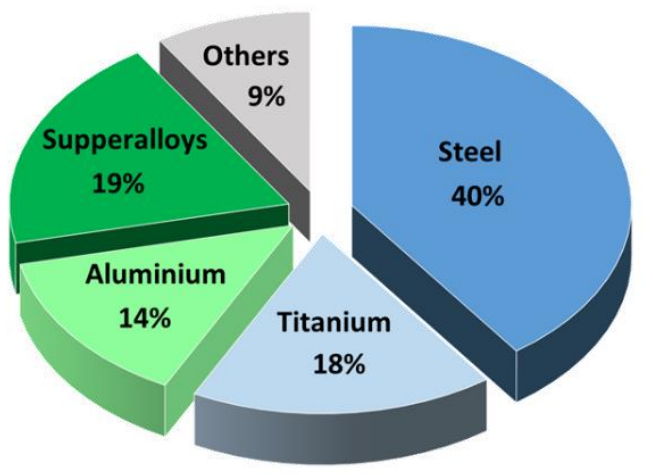

Dissimilar Pulsed Laser Joints
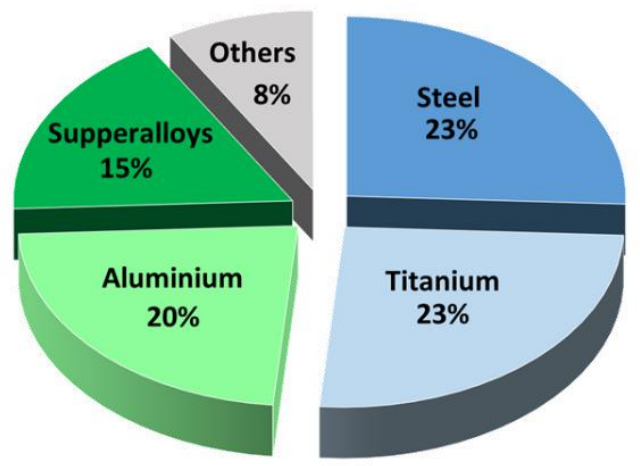

Figure 6. Material division of the pulsed laser welding articles.

\section{Materials}

Since pulse laser welding imposes permanent changes in metallurgical and mechanical properties, the chemical composition and its effect have to be carefully evaluated. Therefore, the process presents different results in steel, titanium, aluminium, and superalloys studies.

\subsection{Steels}

Even with the wide knowledge available regarding the welding process of steels using conventional fusion processes, some joints require a specific heat distribution to generate sound welds. In this context, the studies of pulsed laser effects have demonstrated the suitable characteristics to weld steels.

\subsubsection{Low Alloy and Carbon Steels}

Investigations developed with pulsed joints on low carbon steel have demonstrated heterogeneous characteristics in the microstructure of the FZ. In the St37 steel, the microstructure of this zone was composed of coarse ferrite grains with few distributions of martensite, while the HAZ contained recrystallised fine grains (Figure 7A-C) [52]. In the St4 steel, as the heat input applied was diminishing, the structure of the FZ changed from fine columnar to coarse dendrites as a consequence of the decreased cooling rates, and for this reason the microstructure varied from grain boundary ferrite to Widmanstätten ferrite, bainite, and martensite (Figure 7D,E) [53]. In AISI 1005 low-carbon steel, different 
sub-zones in the welded region were noted due to various thermal cycles generated by the overlapped pulses (Figure 7F-H) [21]. The high temperature reached during the process re-melted the upper zone (Z3), generating lath martensite. However, in the middle zone, the under melting point temperature developed tempered martensite and ferrite (Z2). Otherwise, lath martensite with columnar grains was noted in the bottom region (Z1), corresponding to the single thermal cycle of the pulsed laser.
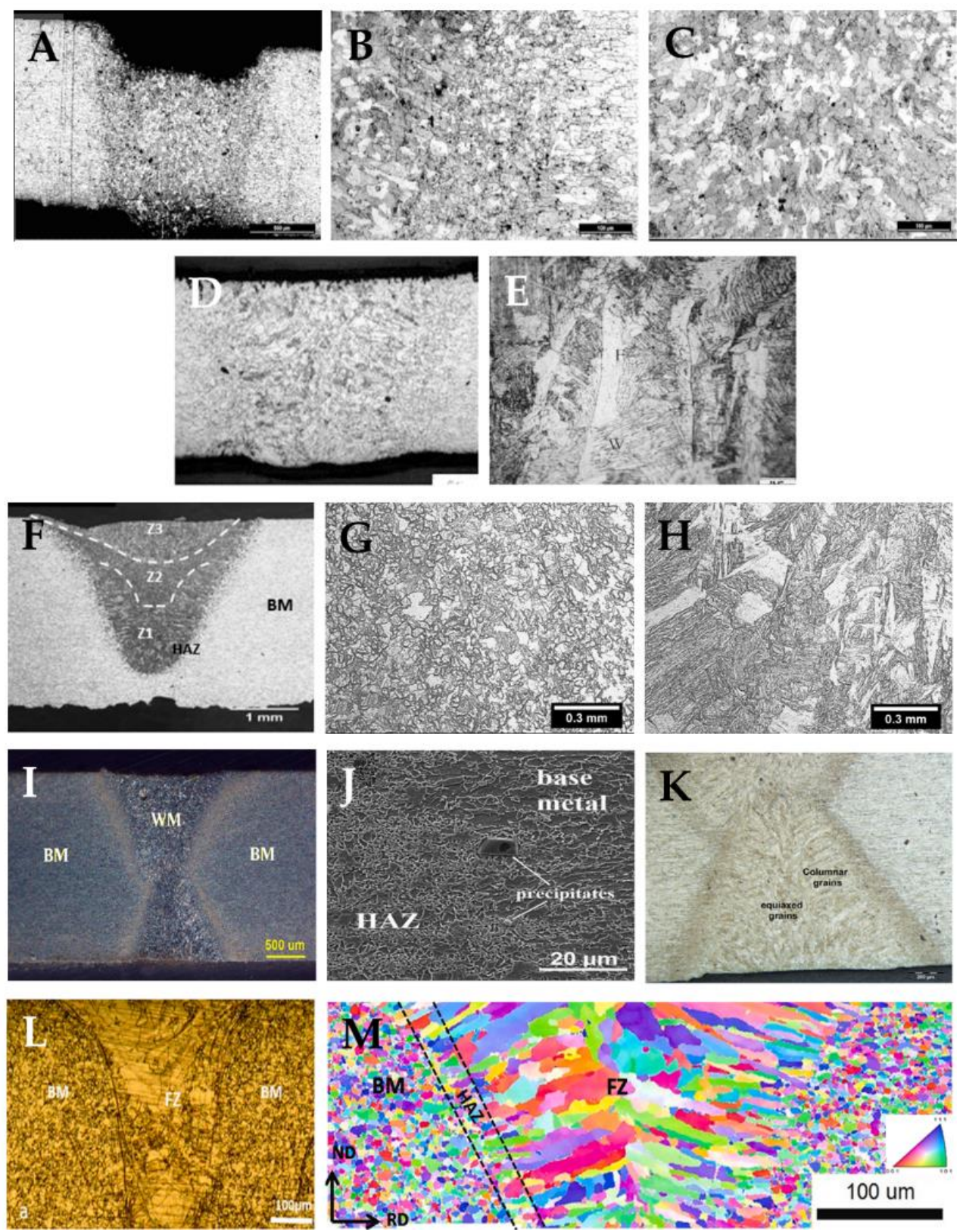

Figure 7. Pulsed laser weldments made of low alloy and carbon steels: St 37 steel (A), and its heataffected zone (HAZ) (B) and FZ (C) [52]; St14 steel (D), and its FZ (E) [53]; AISI 1005 (F), and its HAZ (G) and FZ (H) [21]; S700MC steel (I), and its HAZ (J) and FZ (K) [54]; and twinning induced plasticity (TWIP) steel (L) and its electron back-scatter diffraction (EBSD) map (M) [55].

When the process was applied to S700MC high-strength low-alloy steel (HSLA), the weld region showed equiaxed grains at the centre surrounded by columnar grains near the base metal. The difference in the cooling rates in each zone was associated with low rates in the centre and high rates in the adjacent area (Figure 7I-K) [54]. The high undercooling 
rates developed by the process promoted the transformation to grain boundary ferrite, acicular ferrite, Widmanstätten, bainite, and lath martensite. Moreover, the process was not able to melt and dissolve the TiN particles observed in the FZ. A narrowed HAZ with fine-grained was observed (less than $100 \mu \mathrm{m}$ ). Using twinning induced plasticity (TWIP) steel, the process modified the microstructure from annealing twins and equiaxed grains with a size of $3 \mu \mathrm{m}$ to elongated grains with up to $45 \mu \mathrm{m}$ in the centre of the FZ (Figure 7L,M) [55]. The high heat input applied on the FZ produced evaporation of $\mathrm{Mn}$ from 17 to $13 \%$, enhancing the tensile load values and reaching $94 \%$ of strength efficiency (Table 1). With ultra-high strength steel 22MnB5, the technique transformed the original perlitic-ferritic microstructure into martensite in the FZ and mixture of ferrite, pearlite, and bainite in the HAZ [19].

\subsubsection{Dual Phase (DP)}

The pulsed laser welding applied on a DP1000 dual phase high-strength steel changed part of the parent ferritic-martensitic microstructure to bainite in the FZ (Figure 8A-C) [56]. With the DP590 steel (Figure 8D,E), the increase of the overlap factor (from -22.5 to 75.5\%) modified the microstructure from lath martensite to bainite in the FZ, conserving the austenite in the grain boundary from the base material (BM) [11]. In terms of mechanical properties, the optimisation of the welding parameters (laser power and pulse duration) performed in DP600 steel generated true stress values in the weld very similar to the $\mathrm{BM}$ (between 700 and $800 \mathrm{MPa}$ ), and the failures did not occur in the FZ [57]. Another investigation with same steel indicated that increases in pulse frequency led to higher tensile values [58]. In the single-sided configuration, the highest tensile strength achieved $81 \%$ of the base metal, and in the double-sided welds, the values reached up to $97 \%$.

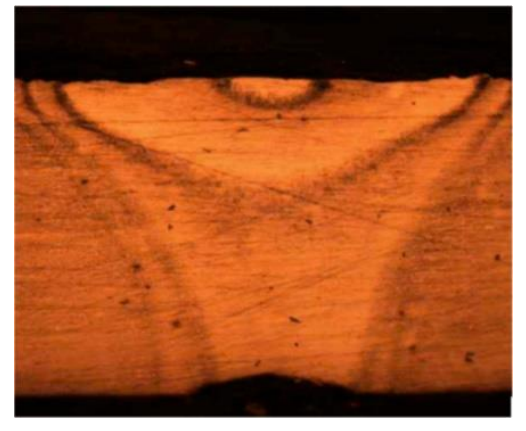

(A)

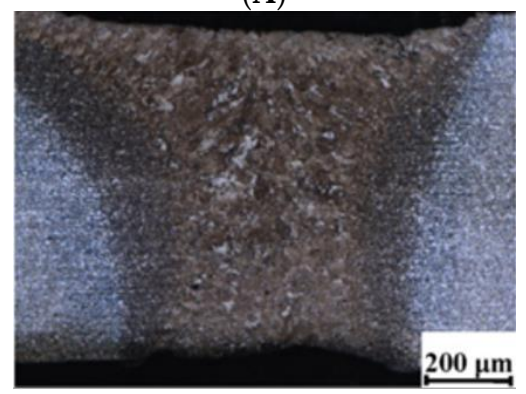

(D)

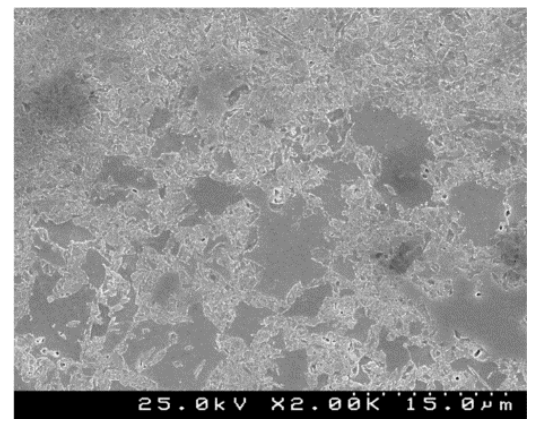

(B)

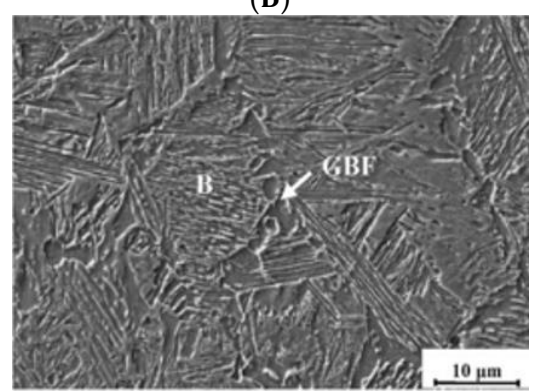

(E)

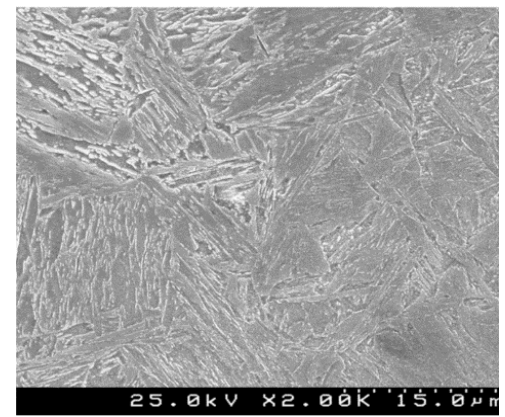

(C)

Figure 8. Pulsed laser weldments made of dual phase steels: DP1000 (A), and its HAZ (B) and FZ (C) [56]; DP 590 joint (D), and its FZ (E) [11].

\subsubsection{Stainless Steel}

This category of steel displays a wide variety of alloys, such as austenitic, ferritic, martensitic, duplex, and precipitation hardening $(\mathrm{PH})$. Each alloy is characterised by singular chemical composition and microstructure developed to achieve sound properties 
for many applications. The importance and high cost of these materials have encouraged several types of studies.

Austenitic stainless steel alloy type 304, widely used for industrial and household applications, showed different sub-zones in the FZ containing columnar dendritic microstructure with dendrite core of vermicular and lathy $\delta$ ferrite delimited by interdendritic austenite (Figure 9A-C) [17]. In the 304L alloy, the pulsed laser provoked mutual transformation of ferrite and austenite in the FZ (Figure 9D,E) [7]. When 301 austenitic stainless steel alloy was welded, the FZ delta ferrite $(\delta)$ changed in finer equiaxed grains and few lathy and skeletal ferrites around the fusion line (Figure 9F,G) [45]. Additionally, the weld interface toward the FZ centre underwent gradual modifications in the solidification structure. The planar mode near the FZ boundary changed to cellular dendritic in the weld centre, passing through the cellular mode.

In researching another significant austenitic alloy extensively applied to industrial sectors, 316 stainless steel, one study found that the pulsed laser promoted coarse grains in the FZ versus fine grains in the HAZ [2]. Another study [38] indicated three different sub-zones generated in the FZ, with epitaxial columnar dendritic growth from the fusion boundary towards the weld centre and elongated intercellular $\delta$-ferrite surrounded by primary austenite. The other sub-zones displayed a refined grain structure with a variety of grain sizes. Using the low-carbon stainless steel 316 in overlap configuration (Figure 9H,I), the FZ demonstrated a fine-grained microstructure with a cellular-dendritic structure [38]. Moreover, columnar grain structure (epitaxial growth) was developed perpendicular to the fusion boundary. On the other side, the HAZ showed coarse grains. In 904L superaustenitic stainless steels, the pulsed process modified the primary austenitic microstructure to fully dendritic in the FZ (Figure 9K,L) [7].

Martensitic stainless steels have excellent mechanical properties and moderate corrosion resistance; however, they have low weldability due to the characteristics of high hardenability and susceptibility to hydrogen induced cold cracking [59]. In this sense, the pulsed process was used for joining cylinders of 420 alloy and the BM microstructure changed from ferrite matrix with precipitation of $\mathrm{M}_{23} \mathrm{C}_{6}$ carbides to fine martensite, $\delta$-ferrite, and some retained austenite in the FZ (Figure 9M,O) [60]. The HAZ had about $25 \mu \mathrm{m}$ of width with coarse $\mathrm{M}_{23} \mathrm{C}_{6}$ carbides, and the different post-welding heat treatment (PWHT) conditions were applied to decrease the hardness of this region $(760 \mathrm{HV})$. As a result, the homogeneous hardness profile displayed a significant reduction due to the tempered martensite in the FZ and the dissolution of the carbides in the HAZ.

Super duplex is a stainless steel category composed of a controlled austenite and ferrite phase balance, delivering high corrosion resistance. This property encourages its use in the oil and gas, paper, and pulp, as well as in petrochemical industries. Employing the pulsed laser in UNS S32750 alloy created an epitaxial microstructure without any detrimental secondary phases, with a maximum of $80 \%$ of ferrite concentration in the FZ (Figure 9P,Q) [61]. In order to restore the equal microstructural balance and guarantee corrosion resistance, the researchers applied the PWHT, and the ferrite was reduced to $64 \%$ in this zone [62]. The exposition of $1050{ }^{\circ} \mathrm{C}$ for $2 \mathrm{~h}$ transformed the excess of columnar ferrite grains into Widmanstätten austenite (Figure 9R).

The precipitation hardening stainless steels are a family of corrosion-resistant alloys in which the addition of copper increases the strength by heat treatment, achieving tensile and yield strengths about 3 or 4 times over 304 and 316 alloys [63]. The most used alloy is AISI 630 (17-4 PH), with about $3 \%$ of copper. It has remarkable properties such as ease of manufacture, high strength, toughness, and good corrosion resistance [64]. Investigation in bead on plate (BOP) configuration indicated excessive spatter and gas pores in some joints, although all welds were free of hot or cold cracks (Figure 9S,T) [64]. Due to the high cooling rates, the pulsed process hardly modifies the martensite microstructures in the FZ. However, the $\delta$-ferrite had interdendritic and lathy morphologies. Four sub-zones in the HAZ with diverse microstructures and microhardness owing to different thermal cycles were detected. In the butt configuration, the spattering and underfill remained, and the PWHT changed 
the microstructure of the FZ. The martensite matrix with $\delta$-ferrite also showed copper and carbide precipitates, which enhanced the FZ hardness and homogenised the HAZ values due to the tempered martensite with Cu-rich precipitates uniformly dispersed.

As a characteristic of the pulsed technique, these investigations carried out with similar joining using different types of steels also demonstrated that the process hardly affected the strength. As described in Table 1, the performance strength resulted in at least $88 \%$ efficiency. The values of hardness observed in the regions are summarised in this table.

Table 1. Selected results of pulsed laser welding apply to steels (approximated values).

\begin{tabular}{|c|c|c|c|c|c|c|}
\hline \multirow{2}{*}{ Alloy } & \multicolumn{3}{|c|}{ Hardness (HV) } & \multicolumn{2}{|c|}{ Strength Performance } & \multirow{2}{*}{ Ref. } \\
\hline & FZ & HAZ & BM & Efficiency & Fracture & \\
\hline St37 & 193 & 168 & 115 & $312.0-96.3 \%$ & - & [52] \\
\hline St14 & 280 & - & - & - & - & [53] \\
\hline AISI 1005 & 390 & 250 & 120 & $287 \mathrm{MPa}-93.7 \%$ & $\mathrm{BM}$ & [21] \\
\hline S700MC & 394 & 335 & 281 & $770 \mathrm{MPa}-100.0 \%$ & $\mathrm{BM}$ & [54] \\
\hline TRIP & 275 & - & 315 & $795 \mathrm{MPa}-94.0 \%$ & - & [55] \\
\hline 22MnB5 & 535 & $200-460$ & 200 & $501 \mathrm{MPa}-99.0 \%$ & $\mathrm{BM}$ & [19] \\
\hline DP1000 & 449 & 316 & 382 & - & - & [56] \\
\hline DP600 & - & - & - & $611 \mathrm{MPa}-91.0 \%$ & - & [58] \\
\hline DP590 & 370 & - & 170 & $635 \mathrm{MPa}-100.0 \%$ & $\mathrm{BM}$ & [11] \\
\hline 301 & 253 & - & 235 & $833 \mathrm{MPa}-99.0 \%$ & - & [45] \\
\hline 304 & $180-250$ & - & 160 & $708 \mathrm{MPa}-112.0 \%$ & - & [17] \\
\hline $304 \mathrm{~L}$ & 210 & - & $180-210$ & $600 \mathrm{MPa}-88.0 \%$ & - & [7] \\
\hline 301 & 254 & - & 234 & $980 \mathrm{MPa}-98.0 \%$ & - & [45] \\
\hline 316 & 195 & 215 & 165 & $477 \mathrm{MPa}$ & - & [2] \\
\hline 316 & $110-270$ & - & 177 & $605 \mathrm{MPa}-98.0 \%$ & - & [17] \\
\hline $316 \mathrm{~L}$ & - & - & - & $609 \mathrm{MPa}-96.0 \%$ & - & [42] \\
\hline $316 \mathrm{~L}$ & 220 & 225 & - & $541 \mathrm{MPa}-95.0 \%$ & - & [38] \\
\hline $904 \mathrm{~L}$ & 218 & - & 190 & $600 \mathrm{MPa}-90.0 \%$ & - & [7] \\
\hline 420 & $450-630$ & 760 & 241 & - & - & [60] \\
\hline 420 PWHT & $210-475$ & $300-450$ & 220 & - & - & [60] \\
\hline 32750 & 180 & - & 120 & $785 \mathrm{MPa}-105.0 \%$ & $\mathrm{BM}$ & [61] \\
\hline 32750 & 375 & - & 330 & - & - & [62] \\
\hline $17-4 \mathrm{PH}$ & 440 & 450 & 400 & $995 \mathrm{MPa}$ & $\mathrm{BM}$ & [64] \\
\hline 17-4 PH PWHT & 520 & 480 & 420 & $1000 \mathrm{MPa}$ & $\mathrm{BM}$ & [64] \\
\hline
\end{tabular}

\subsubsection{Dissimilar Joints}

In some industrial fields, the combined materials have been an alternative to reduce costs associated with the increment of component work life. Nevertheless, joining dissimilar materials has been a challenge from a metallurgical point of view. In this sense, pulsed laser welding has shown significant results. The FZ of joints made with AISI 321 austenitic and AISI 630 precipitation hardening stainless steels (17-4 PH) showed refined martensite developed near the AISI 630 and delta ferrite microstructure in the centre (Figure 10A-C) [63]. Otherwise, near the AISI 321, the amount of martensite significantly diminished, which was replaced by ferrite and austenite contends dendrite and cellular structures. Due to high heat input, the solidification cracks nucleated at the AISI 321 side originated from the weld centre towards the BM. The hardness measurements displayed 
peak value in the AISI 630 fusion boundary $(600 \mathrm{HV})$ due to the martensite microstructure, followed by a reduction towards the AISI 321 parent metal (about $250 \mathrm{HV}$ ).
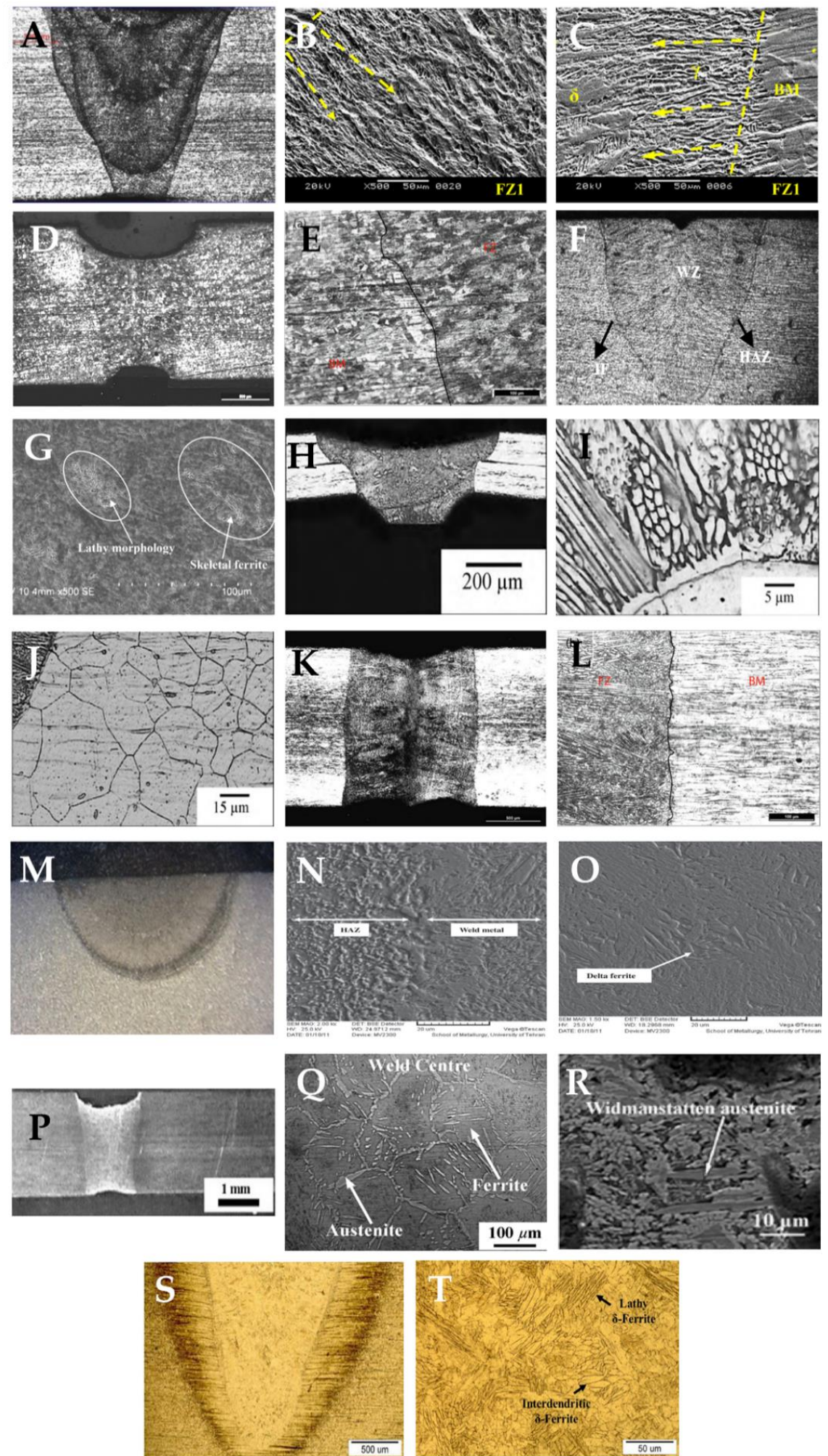

Figure 9. Pulsed laser weldments made of stainless steels: 304 (A), its HAZ (B) and FZ (C) [17]; 304L (D) and its weld interface (E) [7]; 301 stainless steel (F) and its FZ (G) [45]; 316L stainless steel (H), its HAZ (I) and FZ (J) [38]; 904L (K) and its weld interface (L) [7]; 420 stainless steel (M) joint and its HAZ (N) and FZ (O) [60]; UNS S32750 (P), its FZ (Q) [61] and FZ with PWHT (R) [62]; and 17-4 PH (S) and its HAZ (T) [64]. 

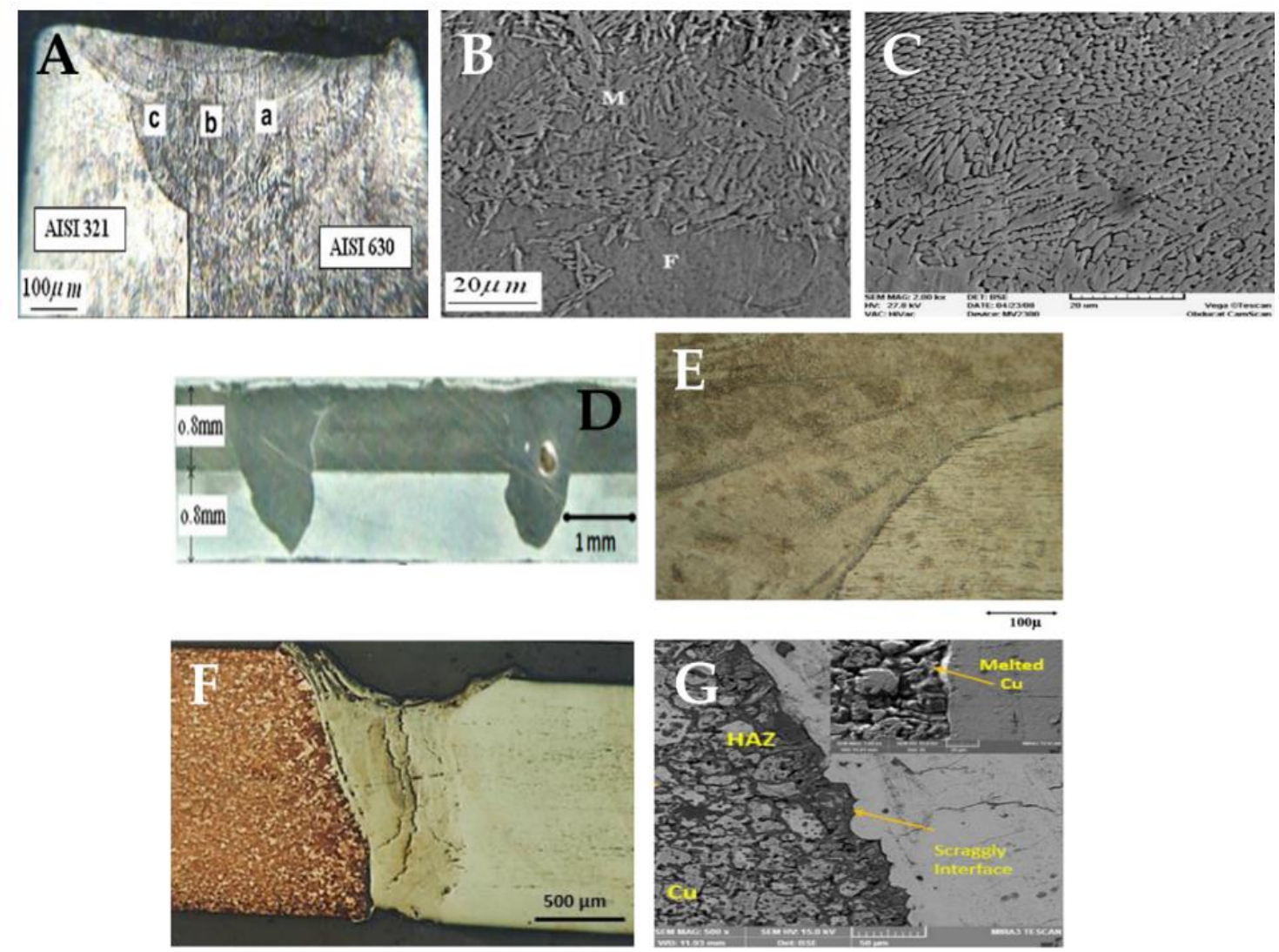

Figure 10. Pulsed laser weldments made of dissimilar stainless steels: AISI 321 and AISI 630 (A), its FZ in the AISI 630 (B) and AISI 321 (C) sides [63], AISI 304L and DIN 11010 (D) and its FZ (E) [65], AISI 304 and copper pure (F) and its weld interface $(G)[66]$.

Pursuing the knowledge of another combination of low carbon with stainless steel, Torkamany et al. [65] explored the joining of AISI 304L and DIN 11010 steel, usually welded by resistance spot welding. The pulsed welding was performed in the overlapped materials configuration with a circular welding path of $6 \mathrm{~mm}$ diameter, as shown in Figure 10D,E. The microstructure of AISI 304L in the FZ revealed fine columnar dendrites with equiaxed grains at the fusion boundary. Moreover, some grain growing and recrystallisation were noted in both HAZs, wherein the SS side displayed $20 \mu \mathrm{m}$ and $80 \mu \mathrm{m}$ on the low-carbon side. The hardness profiles performed in each material exposed higher values in the FZ than the BMs. Regarding DIN 11010, the peak (about 436 HV) reached more than double the BM (about $160 \mathrm{HV}$ ). Moreover, in the AISI $304 \mathrm{~L}$, the values were 1.5 times more than the BM ( 450 and $250 \mathrm{HV}$, respectively). The tensile-shear tests revealed a maximum of $6.04 \mathrm{kN}$ due to the large volume of the carbon steel in the FZ.

Stainless steel was also joined to copper by Nguyen et al. [66] using AISI 304 and pure copper. Cracks were noted in the AISI 304 side of the weld bead (Figure 10F,G), and the FZ displayed vermicular dendrite and dendritic layers of austenite with columnar dendritic structure growing from the boundaries towards the centre of the FZ. On the opposite side of the joint, both HAZ towards the FZ and the narrow FZ interface area of the melted copper experienced gradual grain growth. The microhardness values from the stainless steel were between 230 and $250 \mathrm{HV}$. The profile exposed a decline of up to $60 \mathrm{HV}$ in the joint, following a 70-90 HV increase toward the copper.

These investigations informed that the pulsed laser process could join several steels in similar or dissimilar materials configuration achieving good properties. The complete information about the details of experiments related to the studies is found in Table 2. 
Table 2. Details of pulsed laser welding conditions applied to steel ${ }^{1}$.

\begin{tabular}{|c|c|c|c|c|c|c|c|c|c|}
\hline Alloy & Category & Thickness (mm) & $\begin{array}{c}\text { Joint } \\
\text { Configuration }\end{array}$ & $\begin{array}{c}\text { Pulsed } \\
\text { Configuration }\end{array}$ & $\begin{array}{l}\text { Equipment } \\
\text { Power (W) }\end{array}$ & $\begin{array}{c}\text { Pulse } \\
\text { Energy (J) }\end{array}$ & $\begin{array}{c}\text { Heat Input } \\
(\mathrm{J} / \mathrm{mm})\end{array}$ & $\begin{array}{c}\text { Peak } \\
\text { Power (kW) }\end{array}$ & Ref. \\
\hline AISI 1005 & Low carbon & 1.70 & Butt & Overlap & 80 & - & - & - & [21] \\
\hline AISI 1070 & High carbon & 1.30 & $\mathrm{BOP}^{2}$ & Spot & 20 & $4.80-5.20$ & $15.0-32.6$ & - & [67] \\
\hline St14 & Low carbon & 0.70 & Butt & Overlap & 400 & - & $19.0-29.0$ & $1.10-2.75$ & [53] \\
\hline TWIP & Twinning-induced plasticity high-Mn & 1.00 & Butt & Overlap & 70 & - & - & $2.00-3.00$ & [55] \\
\hline 22Mnb5 & Ultra-high-strength steels & 1.60 & Butt & Overlap & 200 & $4.00-7.20$ & - & $1.00-1.80$ & [19] \\
\hline DP1000 & Dual-phase high-strength steels & 1.00 & $\mathrm{BOP}^{2} / \mathrm{butt}$ & Spot, overlap & 300 & - & - & $2.40-10.32$ & {$[56]$} \\
\hline DP600 & Dual phase & 0.80 & Butt & Overlap & 300 & 38.40 & - & - & [57] \\
\hline DP600 & Dual phase & 1.00 & Butt & Overlap & 300 & 26.40 & - & - & [58] \\
\hline DP 590 & Dual phase & 1.00 & Butt & Overlap & 300 & 8.80 & $5.5-30.0$ & 1.60 & [11] \\
\hline 301 & Austenitic stainless steel & 1.60 & Butt & Overlap & 600 & - & - & $0.35-0.55$ & [45] \\
\hline 304 & Austenitic stainless steel & 1.50 & Butt & Overlap & - & - & - & $0.40-0.49$ & {$[17]$} \\
\hline $304 \mathrm{~L}$ & Austenitic stainless steel & 1.40 & Butt & Overlap & - & 17.00 & - & - & [7] \\
\hline 316 & Austenitic stainless steel & 0.45 & Butt & Overlap & 250 & - & - & - & [2] \\
\hline $316 \mathrm{~L}$ & Austenitic stainless steel & 0.80 & Butt & Overlap & 70 & - & - & $1.65-1.85$ & [42] \\
\hline $316 \mathrm{~L}$ & Austenitic stainless steel & 0.10 & Lap & Overlap & - & $1.00-2.25$ & - & - & [38] \\
\hline 420 & Martensitic stainless steel & 2.00 & Butt & Overlap & 100 & - & - & - & [60] \\
\hline $904 \mathrm{~L}$ & Superaustenitic stainless steel & 1.40 & Butt & Overlap & - & 17.00 & - & - & [7] \\
\hline UNS S32750 & Super duplex stainless steel & 1.30 & Butt & Overlap & 600 & 29.00 & - & 0.50 & [62] \\
\hline UNS S32750 & Super duplex stainless steel & 2.00 & Butt & Overlap & 550 & - & $120.0-330.0$ & $0.50-0.55$ & [61] \\
\hline $17-4 \mathrm{PH}$ & Precipitation hardening & 3.00 & $\mathrm{BOP}^{2}$, butt & Spot, overlap & 300 & - & $60.0-129.0$ & - & [64] \\
\hline $321 / 630$ & Stainless steel/precipitating hardness & 0.60 & Butt & Overlap & 80 & - & - & - & [63] \\
\hline DIN 11010/304L & Low-carbon/austenitic stainless steel & 0.80 & Lap & Overlap & 400 & - & $12.9-19.3$ & $1.50-2.20$ & [65] \\
\hline $304 / \mathrm{Cu}$ & Austenitic stainless steel/Cu & 1.50 & Butt & Overlap & 750 & - & - & - & {$[66]$} \\
\hline
\end{tabular}

${ }^{1}$ _-Argon shielding gas applied in all studies. ${ }^{2}$ - $\mathrm{BOP}$ (bead on plate). 


\subsection{Titanium}

Titanium alloys are widely known for their high strength, low density, high operating temperatures, and good corrosion resistance, related to the stable oxide development on the surface $[22,68]$. Therefore, an increase in the application of titanium alloys has been noticed in numerous sectors of the industry due to these properties, especially in the aerospace, medical, automotive, and energy supply sectors [36,69,70]. Other remarkable properties such as low coefficients of thermal expansion and thermal conductivity, which together diminish heat dissipation and thermal stress, make these alloys suitable for the welding process [71]. However, the elevated melting point (about $1670^{\circ} \mathrm{C}$ ) requires high heat input to achieve this thermal stage. Among the welding processes, laser welding draws special attention on favourable laser absorption and small affected area, as well as having less energy involved in comparison with other methods [71].

The magnitude of these properties varies according to the alloying composition and the condition of the material. From the metallurgical perspective, the titanium alloys have a crucial behaviour related to their crystal structure. The transformation between $\alpha$ (hexagonally close-packed) and $\beta$ (body-centred cubic-BBC) microstructures supports the possibility of modification of the properties, especially the strength performance [69]. Among the titanium alloys, the most used in several industrial applications is the Ti6Al4V because of its high strength characteristic [70,72]. In this sense, several investigations have reported on the impact on the metallurgical and mechanical properties developed during pulsed laser welding operations. As the FZ is the region subjected to the higher heat input, the microstructure created is a cooling cycle result developed during solidification of the weld pool beyond $\beta$-transus temperature (about $995^{\circ} \mathrm{C}$ ). All investigations detected a martensitic $\alpha^{\prime}$ in this region, differing only in its shape (Figure 11) [69,72-74]. In the study by [74], the $\alpha^{\prime}$ had acicular morphology containing thin needles $\alpha^{\prime}$ with average size between 0.8 and $1.5 \mu \mathrm{m}$; in the study of [73], there was an average length of $11.5 \mu \mathrm{m}$ and a thickness of $415 \mathrm{~nm}$. On the other hand, the same convergence of microstructure was not noted in the HAZs. This region was characterised differently in some studies, as a mixture of martensitic $\alpha^{\prime}$, acicular $\alpha$, and primary $\alpha$ in [69]; $\alpha, \alpha^{\prime}$, and $\beta$ in [74]; and acicular $\alpha^{\prime}$ and blocky $\alpha$ phases in [72].

Aside from the Ti6Al4V, other titanium alloys were pulsed laser welded, and independently of the chemical composition, the low heat input and a relatively higher cooling rate developed $\alpha^{\prime}$ martensite in the welded region. Moreover, Ti-5Al-2.5Sn joints showed a considerable fined aspect of this phase (Figure 12A,B) [75]. In the case of Ti-2Al-1.5Mn alloy (Figure 12C-E), the HAZ displayed 2 distinguished sub-zones: partially or fully transformed microstructures [76]. The partial zone showed, besides the original $\alpha$ and $\beta$ phases, $\alpha$ and martensite $\alpha^{\prime}$ phases. However, the full transformation was composed of equiaxed prior $\beta$-grains and acicular $\alpha^{\prime}$ phase within the equiaxed grain. Concerning Ti49.4Ni50.6 TiNi shape memory alloy, both coarse and heterogeneous grains of the BM were transformed to fine equiaxed crystals in the centre of the FZ, surrounded by columnar crystals in the HAZ (Figure 12F-H) [77].

Since the pulsed joint of Ti3Al-Nb alloy displayed pores associated with the Al evaporation in the FZ, $\mathrm{Nb}$ was applied as a filler material and avoided the formation of these defects (Figure 12I,J) [78]. A non-uniform weld zone was created with a white region ( $\mathrm{NbTi}$ solid solution) and a grey region with columnar crystal and dendrite structure.

Table 3 summarises the hardness values measured in the welding seam of titanium similar joints, as well as the strength properties.

Apart from similar joints, some engineering conditions have demanded strategic characteristics of different alloys, requiring dissimilar welding configurations. In this case, contrast on the microstructure and mechanical properties can be significant, depending on the materials' physical and thermal properties. In this regard, a microstructure modification was noted in the joining of Ti-22Al-25Nb and TA15 alloys (Figure 13A-C) [79]. The TA15 parent material with $\beta$ precipitated in $\alpha$ matrix generated three HAZ sub-zones defined as recrystallised, fine-grained, and coarse-grained. Towards the FZ, the HAZ presented 
a $\beta$ phase reduction, developing coarse $\alpha$ and $\alpha^{\prime}$ martensitic phases. Similar behaviour was observed in the Ti-22Al-25Nb side, from the BM microstructures (equiaxed $\alpha 2$ and lath $\mathrm{O}$ phase dispersed in the $\mathrm{B} 2$ matrix) to HAZ, creating three sub-zones containing B2 single-phase zone, $\alpha 2+B 2$ two-phase zone, and an $\alpha 2+\mathrm{O}+\mathrm{B} 2$ three-phase zone. Lastly, the FZ exhibited a dendritic structure with grains growing perpendicular in the extremities, and equiaxed grains in the centre, as well as a minor amount of dispersed acicular martensitic $\alpha^{\prime}$. In the solidification stage, the joints of Ti6Al4V and NiTiNb shape memory created the $\mathrm{Ti}_{2} \mathrm{Ni}, \mathrm{NbNi}_{3}$, and $\mathrm{AlNbTi}_{2}$ brittle intermetallic phases associated with cracking formation (Figure 13D) [80]. Meanwhile, the same intermetallic compounds (IMC) from welding Fe and Ti achieved positive outcomes. A pure titanium and 304 stainless steel crack-free weld were achieved in an overlapped configuration with a small amount of these IMC and strengthening of the joint (Figure 13E) [37]. The overlapped joints developed dendritic microstructure in the middle of the $\mathrm{FZ}$ (zone 5), $\mathrm{Fe}_{2} \mathrm{Ti}$ brittle phase near the weld interface, and FeTi phases in the upper part of welds. In lap joins with Ti6Al4V and AA6060, the pulsed process generated almost a full penetration with cracks in the weld interface (Figure 13F-H), as well as brittle phases TiAl, TiAl2, and TiAl3 [81]. Zones characterised as Al-rich and Ti-rich were also noted near the interface. These intermetallics negatively influenced the tensile shear strength, where the peak value was $43.43 \mathrm{MPa}$.
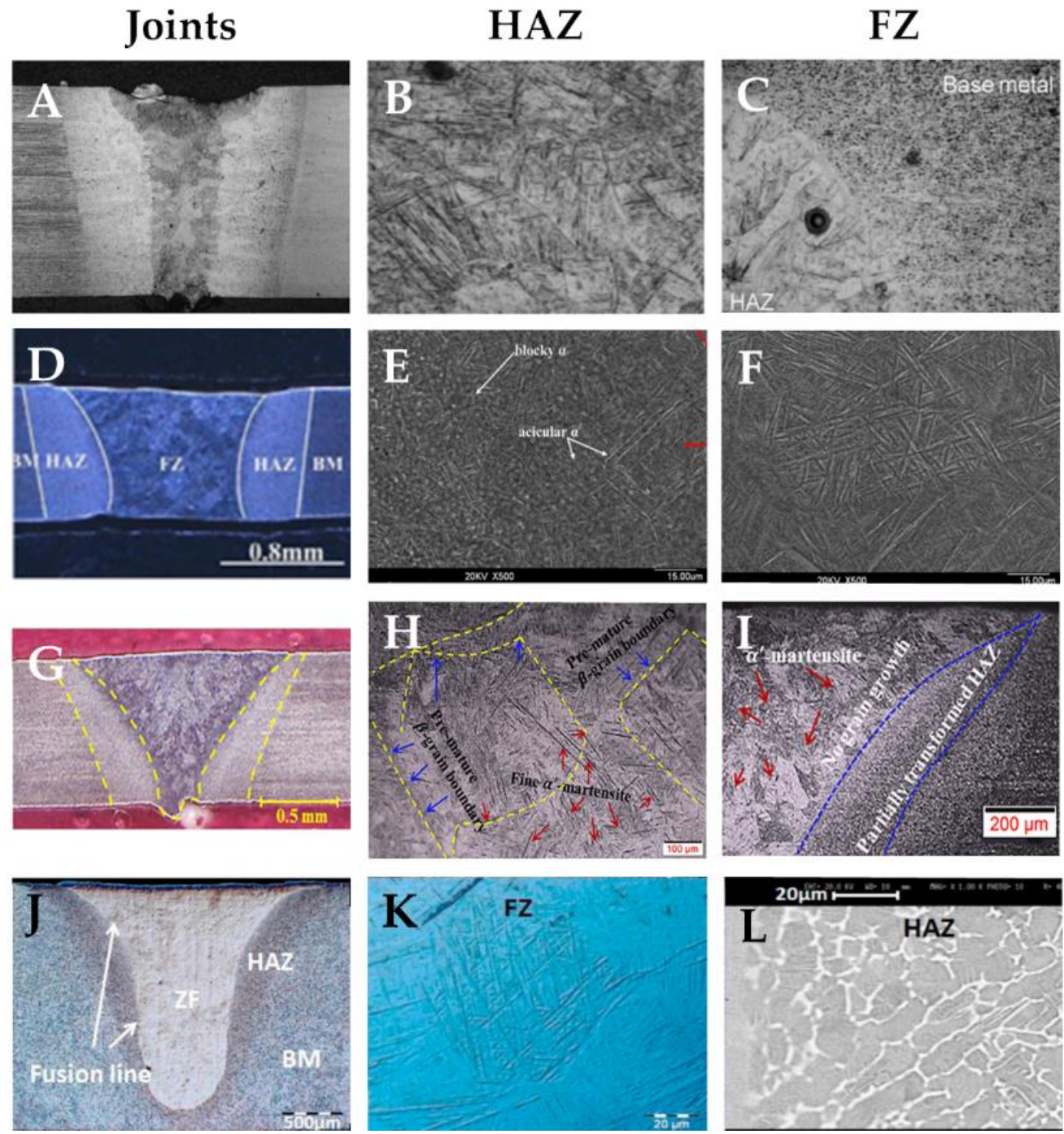

Figure 11. Pulsed laser weldments made of Ti6Al4V. In (A-C) [69], (D-F) [72], (G-I) [73], (J-L) [74]. 

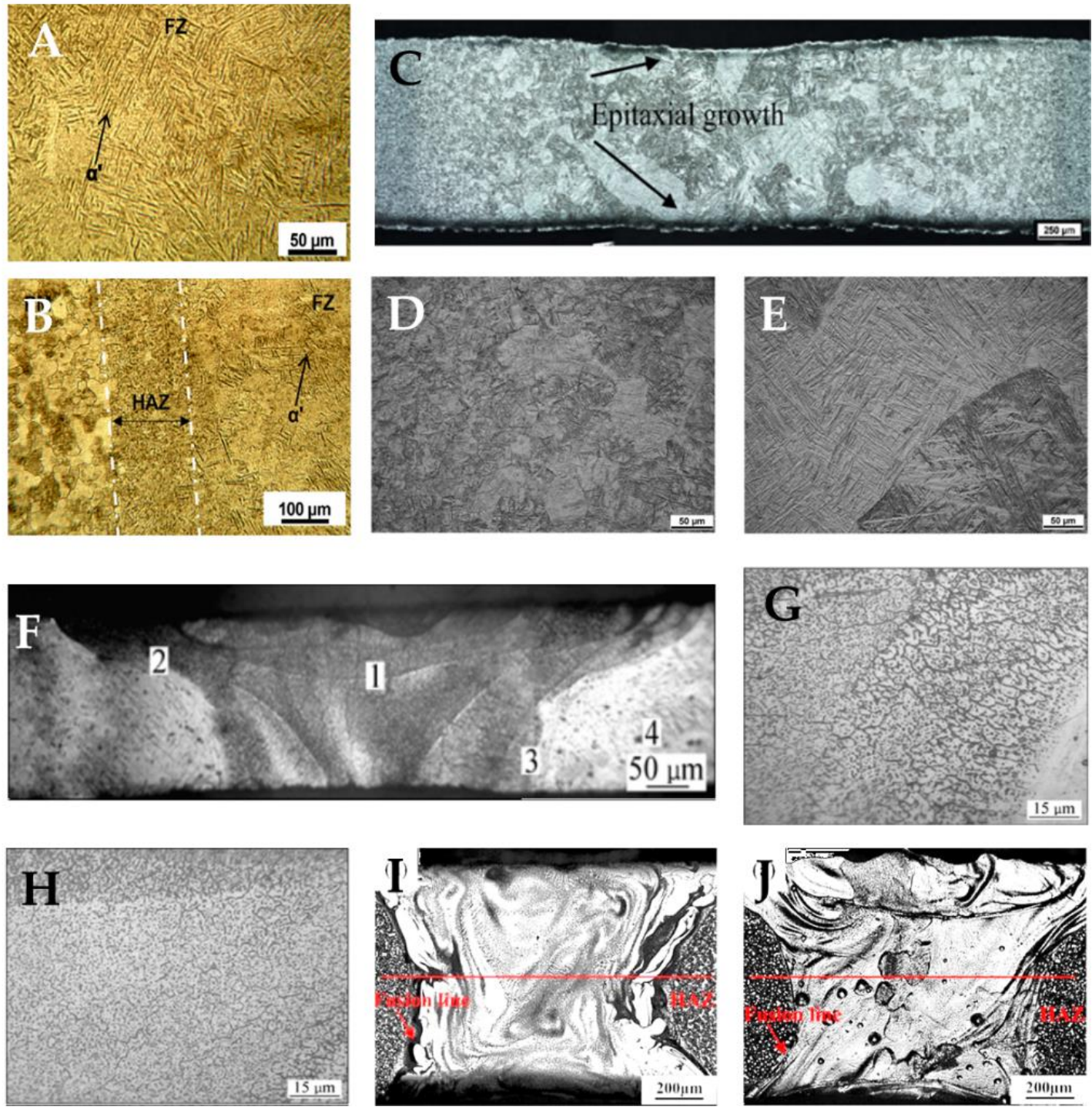

Figure 12. Pulsed laser weldments made of titanium: Ti-5Al-2.5Sn FZ (A) and HAZ (B) [75]; Ti-2Al-1.5Mn (C), its FZ (D) and HAZ (E) [76]; Ti49.4Ni50.6 TiNi (F), its FZ (G) and HAZ (H) [77]; Ti3Al-Nb (I) and Ti3Al-Nb with pure Nb filler metal (J) [78].

Table 3. Selected results of pulsed laser welding apply to similar titanium joints (approximated values).

\begin{tabular}{|c|c|c|c|c|c|c|}
\hline \multirow{2}{*}{ Alloy } & \multicolumn{3}{|c|}{ Hardness (HV) } & \multicolumn{2}{|c|}{ Strength Performance } & \multirow{2}{*}{ Ref. } \\
\hline & FZ & HAZ & BM & Efficiency & Fracture & \\
\hline Ti6Al4V & $500-520$ & $360-425$ & 325 & $507.8 \mathrm{MPa}-47.0 \%$ & - & [69] \\
\hline Ti6Al4V & $360-370$ & $340-350$ & 324 & $1134 \mathrm{MPa}-93.0 \%$ & $\mathrm{BM}$ & [72] \\
\hline Ti6Al4V & - & - & - & $1138 \mathrm{MPa}-102.0 \%$ & $\mathrm{BM}$ & [73] \\
\hline Ti6Al4V & $375-390$ & $350-400$ & 320 & $1191 \mathrm{MPa}-108.0 \%$ & - & [74] \\
\hline Ti-2Al-1.5Mn & $235-280$ & $235-275$ & 215 & - & - & [76] \\
\hline Ti-5Al-2.5Sn & $385-405$ & $354-390$ & 343 & $806 \mathrm{MPa}-95.2 \%$ & $\mathrm{BM}$ & [75] \\
\hline Ti49.4Ni50.6 & - & - & - & $683 \mathrm{MPa}-95.0 \%$ & - & [77] \\
\hline $\mathrm{Ti} 3 \mathrm{Al}-\mathrm{Nb}$ & $385-395$ & $375-380$ & 365 & $330 \mathrm{MPa}-37.2 \%$ & $\mathrm{FZ}$ & [78] \\
\hline $\begin{array}{l}\text { Ti3Al-Nb } \\
\text { Nb Filler }\end{array}$ & $355-375$ & $375-380$ & 365 & $724 \mathrm{MPa}-81.7 \%$ & FZ/HAZ & [78] \\
\hline
\end{tabular}


As an alternative to avoid the formation of these brittle compounds, some studies evaluated the use of third materials as an interlay barrier. The use of $\mathrm{Nb}$ was proposed since it has no intermetallic compounds with $\mathrm{Ti}$ and, as a result, full penetrated joints were obtained (Figure 13I,J) [82,83]. Regions richer in $\mathrm{Ti}$ or $\mathrm{Nb}$ with more melting in the Ti side were observed due to its lower melting point. Additionally, all tensile samples broke in the $\mathrm{Nb} \mathrm{BM}$, far from the joint, indicating the absence of brittle phases [82]. Vanadium was also used to weld Ti6Al4V and AISI 301L stainless steel with the pulsed laser beam placed on the $\mathrm{V}$ interlayer at $0.25 \mathrm{~mm}$ from the Ti6Al4V interface in order to prevent the mixture of Ti and SS (Figure 13K,L) [84]. Therefore, three zones were formed: melted at the Ti-V joint, un-melted V, and the weld at the V-SS interface. The first zone showed cellular microstructure of continuous solid solution with $(\beta \mathrm{Ti}, \mathrm{V})$ compounds rich in $\mathrm{V}$. On the other hand, the weld at the V-SS interface was composed of continuous solid solutions of $(\mathrm{Fe}, \mathrm{V})$ containing $\mathrm{V}$ and $\gamma$-Fe. Moreover, copper was applied to join the same alloys with the beam on the AISI 301L side at $0.2 \mathrm{~mm}$ from the copper interface (Figure 13M,O) [85]. As a result, the large weld zone of $\mathrm{Cu}-\mathrm{SS}$ was created with a cellular dendritic structure and $\gamma$-Fe phase without Ti-Fe intermetallics, although micro-cracks were presented. Alongside this region, un-melted copper zone with an interface exhibiting columnar grains was observed. Additionally, the higher thermal conductivity of $\mathrm{Cu}$ facilitated the heat flow and changed the microstructure of the $\mathrm{Ti} / \mathrm{Cu}$ interface, creating a thin layer of $40 \mu \mathrm{m}$ composed of thick lamellar structure with $\mathrm{Cu}_{2} \mathrm{Ti}$ and $\mathrm{Cu}_{4} \mathrm{Ti}$ phases. In this sense, the $\mathrm{Cu}$ barrier reduced the formation of Ti-Fe intermetallics. Nevertheless, $\mathrm{Ti}-\mathrm{Cu}$ compounds negatively influenced the strength, as shown in Table 4.

Table 4. Selected results of pulsed laser welding apply to dissimilar titanium alloys (approximated values).

\begin{tabular}{|c|c|c|c|c|c|}
\hline \multirow{2}{*}{$\begin{array}{c}\text { Joint } \\
\text { Alloys }\end{array}$} & \multicolumn{2}{|c|}{ Hardness (HV) } & \multicolumn{2}{|c|}{ Strength Performance } & \multirow{2}{*}{ Ref } \\
\hline & FZ & BM & Efficiency & Fracture & \\
\hline $\begin{array}{c}\text { Ti-22Al- } \\
\text { 25Nb/TA15 }\end{array}$ & $271-290$ & $\begin{array}{c}\text { Ti-22Al-25Nb: } 350 \\
\text { TA15: } 320\end{array}$ & $\begin{array}{c}1019 \mathrm{MPa} \\
92.0 \% \mathrm{TA} 15 \\
86.0 \% \mathrm{Ti}-22 \mathrm{Al}-25 \mathrm{Nb}\end{array}$ & $\mathrm{FZ}$ & [79] \\
\hline $\mathrm{Ti6Al4V/Nb}$ & $175-300$ & $\begin{array}{l}\text { Ti6Al4V: } 320 \\
\text { Nb: } 80\end{array}$ & $\begin{array}{c}269 \mathrm{MPa} \\
29.2 \% \mathrm{Ti} 6 \mathrm{Al} 4 \mathrm{~V} \\
100.0 \% \mathrm{Nb}\end{array}$ & $\mathrm{Nb} / \mathrm{BM}$ & [82] \\
\hline Ti6Al4V / AA6060 & - & - & $43.3 \mathrm{MPa}$ & - & [81] \\
\hline CP Ti/304 & $550-750$ & $\begin{array}{c}\text { Ti: } 150 \\
\text { 304SS: } 325\end{array}$ & $\begin{array}{l}200 \mathrm{MPa} \\
70.0 \% \mathrm{Ti}\end{array}$ & - & [37] \\
\hline $\begin{array}{c}\text { Ti6Al4V /301L } \\
\text { with V interlayer }\end{array}$ & $\begin{array}{l}\text { Ti6Al4V: } 470 \\
\text { 301L: } 300 \\
\text { V: } 160\end{array}$ & $\begin{array}{l}\text { Ti6Al4V: } 345 \\
\text { 301L: } 320\end{array}$ & $587 \mathrm{MPa}$ & $\mathrm{Ti}-\mathrm{V}$ interface & [84] \\
\hline $\begin{array}{c}\text { Ti6Al4V /301L } \\
\text { with Cu interlayer }\end{array}$ & $\begin{array}{l}\text { FZ: } 315 \\
\text { Cu: } 150\end{array}$ & $\begin{array}{l}\text { Ti6Al4V: } 345 \\
\text { 301L: } 320\end{array}$ & $\begin{array}{c}320 \mathrm{MPa} \\
35.7 \% \mathrm{Ti} 6 \mathrm{Al} 4 \mathrm{~V} \\
58.2 \% 301 \mathrm{~L}\end{array}$ & $\mathrm{Ti} / \mathrm{Cu}$ layer & [85] \\
\hline
\end{tabular}

These investigations prove that the pulsed laser process is capable of joining different titanium alloys producing satisfactory properties. Joints performed with Ti6Al4V indicated similar microstructure evolution developed by the heat provided by the process. The use of alternative filling material was also applied to suppress the crack formation, being a viable option to avoid this kind of defect. Other studies indicated the possibility to join in overlap configuration, amplifying the field of these materials' application. In dissimilar welds, even with a significant contrast between the properties and the formation of intermetallic phases, free crack weld seams were made. Further experimental details applied in those investigations are summarised in Table 5. 

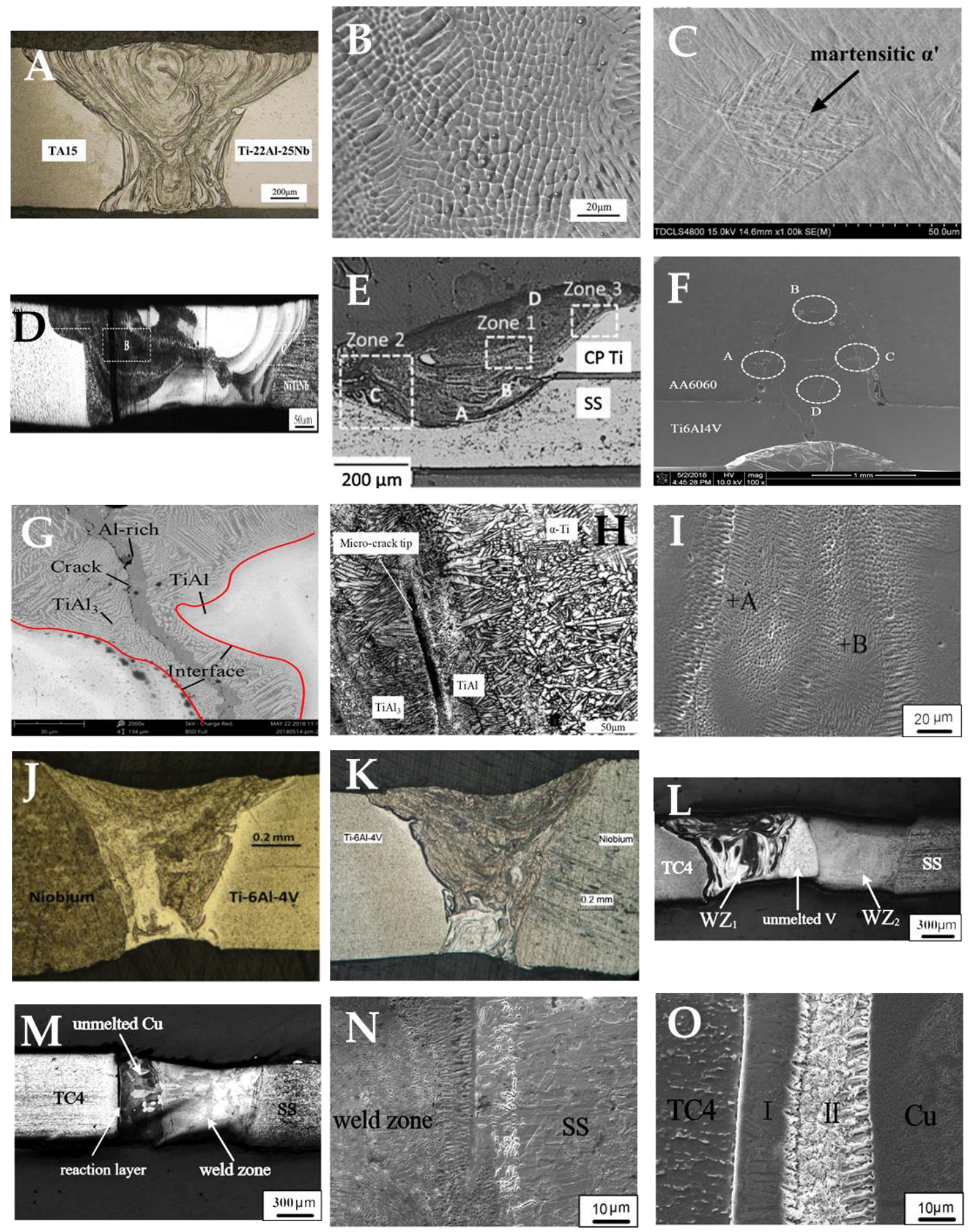

Figure 13. Pulsed laser weldments made of dissimilar titanium: Ti-22Al-25Nb and TA15 (A), its FZ (B) and HAZ (C) [79]; Ti6Al4V and NiTiNb (D) [80]; pure Ti and 304 stainless steel (E) [37]; Ti6Al4V and AA6060 lap joint (F), its interface (G) and crack (H) [81]; Ti6Al4V and pure Nb (I) [83]; Ti6Al4V and pure Nb (J) [82]; Ti6Al4V and 301L stainless with V interlayer (K) and its FZ (L) [84]; Ti6Al4V and 301L stainless steel with copper interlayer (M) and its weld interface (N,O) [85]. 
Table 5. Details of welding conditions applied to titanium pulsed laser ${ }^{1}$.

\begin{tabular}{|c|c|c|c|c|c|c|c|c|}
\hline Alloy & $\begin{array}{c}\text { Thickness } \\
(\mathrm{mm})\end{array}$ & $\begin{array}{c}\text { Joint } \\
\text { Configuration }\end{array}$ & $\begin{array}{c}\text { Pulsed } \\
\text { Configuration }\end{array}$ & $\begin{array}{c}\text { Equipment } \\
\text { Power (KW) }\end{array}$ & $\begin{array}{c}\text { Pulse } \\
\text { Energy (J) }\end{array}$ & $\begin{array}{c}\text { Heat Input } \\
(\mathrm{J} / \mathrm{mm})\end{array}$ & Peak Power (kW) & Ref. \\
\hline Ti6Al4V & 0.80 & Butt & Overlap & - & $6.0-13.0$ & - & - & [73] \\
\hline Ti6Al4V & 0.80 & Butt & Overlap & - & - & - & - & [72] \\
\hline Ti6Al4V & 1.50 & Butt & Overlap & - & - & - & $2.6-5.2$ & [86] \\
\hline Ti6Al4V & 3.00 & $\mathrm{BOP}^{2}$ & Overlap & 0.75 & - & - & - & [70] \\
\hline Ti6Al4V & 3.00 & Butt & Overlap & 0.60 & $5.6-13.4$ & - & - & [69] \\
\hline Ti-5Al-2.5Sn & 1.60 & Butt & Overlap & - & - & - & - & [75] \\
\hline Ti49.4Ni50.6 & 0.20 & Butt & Overlap & 0.08 & - & - & - & [77] \\
\hline Ti-24Al-15Nb & 1.00 & Butt & Overlap & - & - & - & - & [78] \\
\hline NiTiNb/Ti6Al4V & $\mathrm{Ni} \mathrm{0.3/0.2} \mathrm{Ti}$ & Butt & Overlap & 0.08 & - & - & - & [80] \\
\hline Ti22A125/TA15 & 1.00 & Butt & Overlap & 4.00 & - & - & 1.3 & [79] \\
\hline Ti6Al4V/Nb & $\mathrm{Nb} 1.00 / 0.85 \mathrm{Ti}$ & Butt & Overlap & 0.40 & $9.0-18.0$ & 27.0 & 1.5 & [82] \\
\hline $\mathrm{Ti} 6 \mathrm{Al} 4 \mathrm{~V} / \mathrm{Nb}$ & $\mathrm{Nb} 1.00 / 0.85 \mathrm{Ti}$ & Butt & Overlap & 3.00 & 15.0 & 37.5 & 1.5 & [83] \\
\hline Ti6Al4V/AA6060 & Ti6Al4V 0.80/1.50 A6060 & Butt & Overlap & 0.30 & - & - & 12.0 & [81] \\
\hline $\mathrm{CP} \mathrm{Ti} / 304 \mathrm{SS}$ & 0.25 & Butt & Overlap & - & - & - & 4.5 & {$[37]$} \\
\hline Ti6Al4V/301L & 0.80 & Butt & Overlap & 1.05 & - & - & - & [84] \\
\hline Ti6Al4V/301L & 0.80 & Butt & Overlap & 1.05 & - & - & - & [85] \\
\hline
\end{tabular}




\subsection{Aluminium}

Aluminium and its alloys are the most widely non-ferrous metals used due to their outstanding characteristics such as excellent corrosion resistance, high strength to weight ratio, and high electrical and thermal conductivities, as well as having a relatively low cost $[9,10,16]$. This combination of favourable properties enables the application of engineering components in an extensive range of industrial sectors, including automobile, aerospace, pressure vessel, and shipbuilding $[9,26,87]$. Nevertheless, joining aluminium alloys involves several challenges. Regarding the physical characteristics, aluminium has high reflectivity, absorbing at a lower wavelength laser energy [88]. Therefore, the laser based on the Nd:YAG source $(\lambda=1.06 \mu \mathrm{m})$ is more appropriate for welding aluminium than the $\mathrm{CO}_{2}(\lambda=10.06 \mu \mathrm{m})$ [9]. Besides this, the high thermal conductivity leads to a fast heat transfer in the weld bead, restricting the concentration of energy, and, in thin sheets, the low viscosity can limit the growth of the weld pool before solidification [9,89-91]. An important issue is the tendency to crack formation during the solidification stage (a phenomena known as solidification cracking) $[9,26,92]$, mainly due to the rapid cooling promoted by laser welding [89]. In this regard, the studies indicate that specific welding parameters can develop crack-free joints.

Vast aluminium alloys have been used to replace conventional materials, bringing their abovementioned properties to produce new devices and components. Like other metal alloys, aluminium alloys are classified by chemical composition and physical properties. In the case of the 5000 series, the alloys are composed of $\mathrm{Mg}$ as the main element, offering good corrosion resistance in marine environments and good weldability. For this reason, researchers have evaluated its application in pulsed laser welding. AA5052 alloy in an overlap joint configuration showed that the energy input variation significantly influenced the precipitates distribution and the crack presence (Figure 14A,B) [89]. Since a higher cooling rate generates fine and equiaxed structure, the homogenous distribution of fine precipitates and the absence of precipitate formation near the FZ interface promotes crack-free welds. On the other hand, a lower cooling rate induces cellular or dendritic structure in welds, leading to joints with cracks exhibiting a network of fine spherical precipitates $(0.07$ to $0.51 \mu \mathrm{m})$. Another study with the AA5052-H3 alloy demonstrated the possibility of producing butt sound welds without cracks varying the welding conditions (Figure 14C,D) [9]. The FZ microstructure was a fine cellular dendritic grain structure with the intermetallic phase $\left(\mathrm{Al}_{0.5} \mathrm{Fe}_{3} \mathrm{Si}_{0.5}\right)$ and columnar structure at the HAZ interface. A study of AA5456 alloy pulsed laser joint revealed that despite the modification of welding parameters, all the welds exhibited cracks (Figure 14E-H) and columnar grain structure in the FZ, known as very susceptible morphology to hot tearing [26]. Nevertheless, the $150{ }^{\circ} \mathrm{C}$ preheating reduced the hot crack susceptibility (solidification and liquation cracking), generating free-crack joints with fine equiaxed grains.

Besides the study of the microstructure and the heat influence on the pulsed joint properties, the effect of element evaporation is concerned in the defect formation, since larger solidification temperature range is often caused by the presence of alloying elements such as $\mathrm{Si}$ and $\mathrm{Mg}$ [9]. AA5754-O pulsed butt welding demonstrated that the porosities decreased with lower heat input due to the lower amount of evaporated and trapped $\mathrm{Mg}$ [93]. In this case, the porosity ratio decreased from 15 to $13 \%$ with the reduction of $\mathrm{Mg}$ evaporation in about $0.1 \%$. This aspect is aligned with the microstructural refinement, which conducted to a $90 \%$ efficiency in joint strength performance.

Other commercial aluminium alloys with both Si and Mg are the 6000 series. They are known for their possibility of improving strength by heat treatment. As welding processes generate different thermal cycles, scientific studies have been developed to comprehend the material affected. Differently from the 5000 alloys, the variation in the heat input did not significantly affect the porosity formation in the AA6022 T4E29 joint since the Mg content was reduced in the BM and the extension of Mg evaporation was condensed [93]. Furthermore, joints even with up to $8 \%$ of pores reached $64 \%$ of strength efficiency. 
Hot cracking is another significant issue due to its high susceptibility to form this defect during the solidification. The tendency is governed by weld pool composition, the parameters and welding process, and the joint restraint to thermal contraction [94-97]. As the process provides the option of pulse shape configuration, other laser beam profiles can be used instead of the usual rectangular shape. In this sense, the study performed by Zhang et al. [94] in AA6061 T6 indicated that a specific range of ramp-down could mitigate the crack formation. A similar strategy was applied in both AA6082 T6 [95] and AA5083 [98], which eliminate the hot cracks due to the moderate solidification rates created (Figure 14I,J). Another approach used to avoid this defect is to apply compressive stress by the peening procedure before welding. Longitudinal cracks were eliminated in AA6061 O; however, the effect was conditioned with the dimensions of the crack (small) or weld pool (higher depth-to-width ratio) [99]. In addition, this method increased the hardness of the HAZ (Table 6).
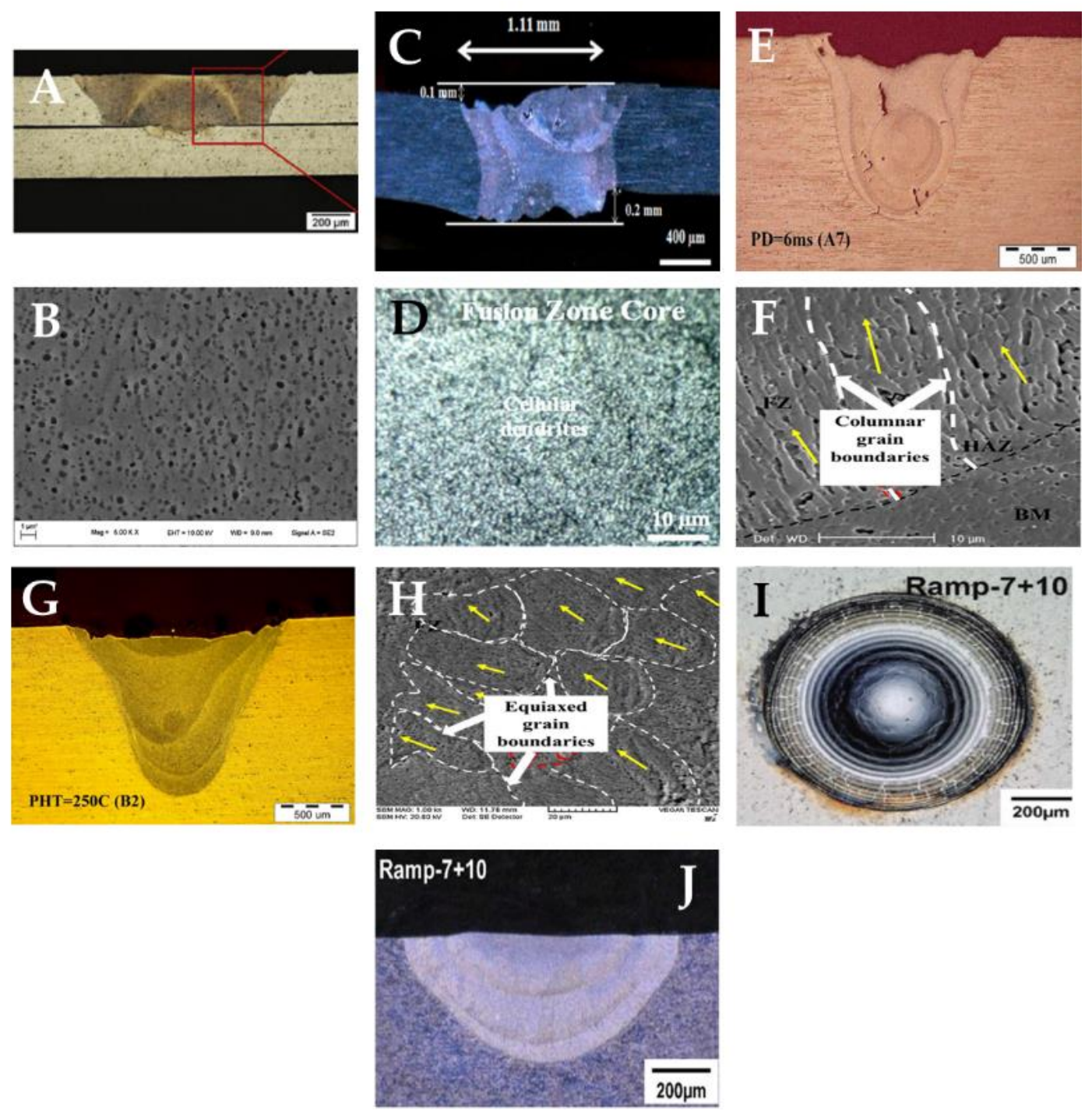

Figure 14. Pulsed laser weldments made of aluminium: AA5052 (A) and its FZ (B) [89]; AA5052-H32 (C) and its FZ (D) [9]; AA5456 (E) and its weld interface (F); AA5456 after PWHT (G) and its FZ (H) [26]; and AA5083 spot (I) and its cross-section (J) [98]. 
Table 6. Selected results of pulsed laser welding applied to similar aluminium alloys (approximated values).

\begin{tabular}{|c|c|c|c|c|c|c|}
\hline \multirow{2}{*}{$\begin{array}{l}\text { Aluminium } \\
\text { Alloy }\end{array}$} & \multicolumn{3}{|c|}{ Hardness (HV) } & \multicolumn{2}{|c|}{ Strength Performance } & \multirow{2}{*}{ Ref. } \\
\hline & FZ & HAZ & BM & Efficiency & Fracture & \\
\hline AA5052 & $58.6-65.6$ & - & $60.1-70.5$ & $140 \mathrm{~N}$ & - & [89] \\
\hline AA5052 H3 & $105.0-120.0$ & 85-105 & 80.0 & $168 \mathrm{MPa}-73 \%$ & - & [9] \\
\hline AA5456 & $95.0-100.0$ & - & 115.0 & - & - & [26] \\
\hline AA5456 PH & $75.0-85.0$ & - & $95.0-100.0$ & - & - & [26] \\
\hline AA5754-O & - & & - & $180 \mathrm{MPa}-90 \%$ & FZ & [93] \\
\hline AA6061 O & $\begin{array}{c}76.0 \\
74.0 *\end{array}$ & $\begin{array}{l}49 \\
61 * \\
\end{array}$ & 45.0 & - & - & [99] \\
\hline AA6022 T4E29 & - & - & - & $149 \mathrm{MPa}-64 \%$ & $\mathrm{FZ}$ & [93] \\
\hline
\end{tabular}

In dissimilar joints between aluminium and steel, the mutual solubility is also an important additional factor. The solubility of $\mathrm{Fe}$ in $\mathrm{Al}$ is almost zero, and the solid-state solubility of $\mathrm{Al}$ into $\mathrm{Fe}$ is low [100]. As a result, the mixture of these materials causes the diffusion of $\mathrm{Al}$ and $\mathrm{Fe}$ atoms at the interface, forming $\mathrm{Fe}-\mathrm{Al}$ intermetallic compounds (IMC) such as Fe-rich phases ( $\mathrm{FeAl}$ and $\left.\mathrm{Fe}_{3} \mathrm{Al}\right)$ and $\mathrm{Al}$-rich phase $\left(\mathrm{FeAl}_{2}, \mathrm{Fe}_{2} \mathrm{Al}_{5}\right.$, and $\left.\mathrm{FeAl}_{3}\right)[20,101,102]$. These compounds are known as brittle and hard phases, with Fe-rich compound hardness reaching ranges between 250 and $520 \mathrm{HV}$, and Al-rich phases from 820 to 1100 HV [101]. This characteristic can deteriorate the weld, and mitigating these intermetallics could enhance quality and strength. The pulse laser process can deliver some advantages to overcome this particularity due to the low heat input involved, as well as the minimised volume of HAZ and the thermal stress [20].

Owing to achieving a sound joint, Indhu et al. [20] studied the joint of AA6061 and galvanised DP600 steel in an overlap configuration (Figure 15A,B). The FZ showed small micro-cracks along with $\mathrm{Fe}_{2} \mathrm{Al}_{5}$ phases. Moreover, the aluminium interface displayed layers of $\mathrm{Fe}_{2} \mathrm{Al}_{5}$ with $\mathrm{FeAl}_{3}$ precipitated as acicular and long needle-shaped compounds. As these compounds have a hard characteristic, the peak of hardness was $510 \mathrm{HV}$ (Table 7), and through the pulse duration balance, the thickness of IMC was controlled in the range of 1-7 $\mu \mathrm{m}$. Moreover, the aluminium interface presented porosities associated with the zinc vapour from the galvanised steel entrapment. These intermetallic phases were also observed in AA5754 and St14 low-carbon steel in an overlapped joint configuration (Figure 15C,D) [101]. Nevertheless, a satisfactory bonding without any macroscopic defects was reached. The intermediate travel speeds provided adequate heat and cooling rate to produce a high tensile strength (Table 7), even with a relatively continuous interface layer with $\mathrm{Fe}_{2} \mathrm{Al}_{5}, \mathrm{FeAl}_{3}$, and $\mathrm{FeAl}_{2}$ compounds. When 316L stainless steel and AA1060 pure aluminium were welded in overlap configuration, the $\mathrm{FZ}$ displayed a wavy interface surrounded by needle-like structures of $\mathrm{FeAl}$ and $\mathrm{FeAl}_{2}$ phases (Figure 15E,F) [87]. Besides the Al-rich phases, the $\mathrm{FZ}$ centre presented other intermetallics composed of $\mathrm{Fe}, \mathrm{Ni}, \mathrm{Cr}$, and Al. As observed, the welding defects (spatter, crack, cavity, and loss of molten material) significantly increased with penetration depth higher than $108 \mu \mathrm{m}$. Regarding the strength performance, a study developed by Pereira et al. [103] indicated that lap joints with AA1050 and DP1000 steel displayed positive values, reaching $88 \%$ of the aluminium base metal (Figure 15G,H). 

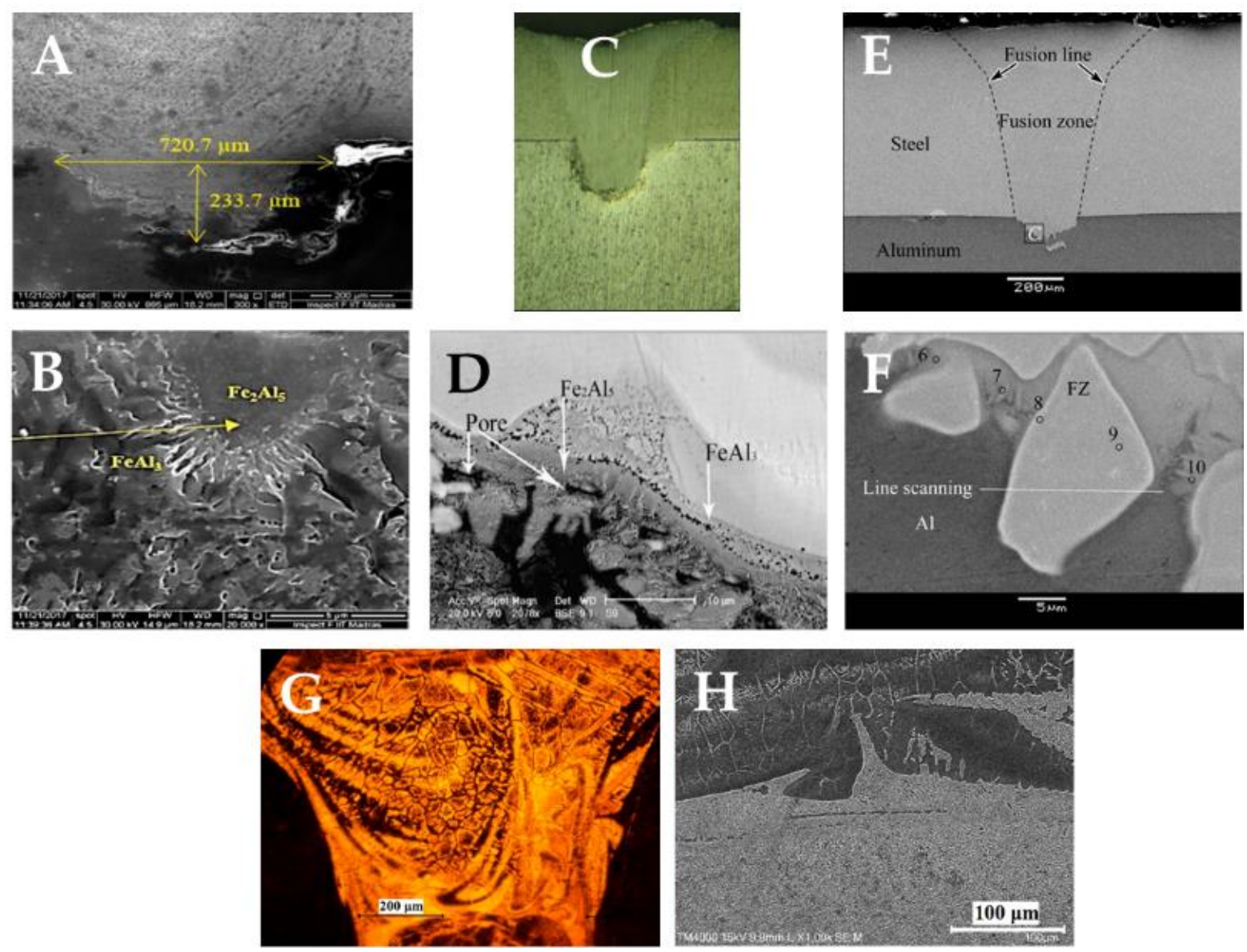

Figure 15. Pulsed laser weldments made of dissimilar aluminium alloys: DP 600 steel and AA6061 (A) and its FZ (B) [20], AA5754 and St14 steel (C) and its weld interface (D) [101], 316L and AA1060 (E) and its weld interface (F) [87], and AA1050 and DP1000 steel $(\mathbf{G})$ and its weld interface $(\mathbf{H})[103]$.

Table 7. Selected results of pulsed laser welding apply to dissimilar aluminium alloys (approximated values).

\begin{tabular}{|c|c|c|c|c|c|c|}
\hline \multirow{2}{*}{ Alloys } & \multicolumn{3}{|c|}{ Hardness (HV) } & \multicolumn{2}{|c|}{ Strength Performance } & \multirow{2}{*}{ Ref. } \\
\hline & FZ & Interface & BM & Efficiency & Fracture & \\
\hline AA6061 & AA6061: 231 & AA6061: 501 & AA6061: 253 & \multirow[t]{2}{*}{-} & \multirow[t]{2}{*}{-} & \multirow[t]{2}{*}{ [20] } \\
\hline DP 600 & DP 600: 267 & DP 600: 419 & DP 600: 66 & & & \\
\hline $\begin{array}{l}\text { AA5754 } \\
\text { St14 }\end{array}$ & $\begin{array}{c}\text { AA5754: } 1150 \\
\text { St14: } 200\end{array}$ & 1200 & $\begin{array}{c}\text { AA5754: } 100 \\
\text { St14: } 150\end{array}$ & $180-300 \mathrm{MPa}$ & - & [101] \\
\hline $\begin{array}{l}\text { AA1060 } \\
\text { 316L }\end{array}$ & 316L: 440 & 700 & $\begin{array}{l}\text { AA1060: } 35 \\
\text { 316L: } 180\end{array}$ & $46 \mathrm{MPa}$ & Interface & [87] \\
\hline
\end{tabular}

The abovementioned investigations demonstrated the crack formation could be avoided, providing sound weld, independently of the alloys involved, even in the dissimilar joints between steel and aluminium. Table 7 displays the mechanical properties of the similar and dissimilar aluminium joints, while Table 8 contains pulsed laser information performed on the study cited for further details. 
Table 8. Details of welding conditions applied to similar and dissimilar aluminium pulsed laser ${ }^{1}$.

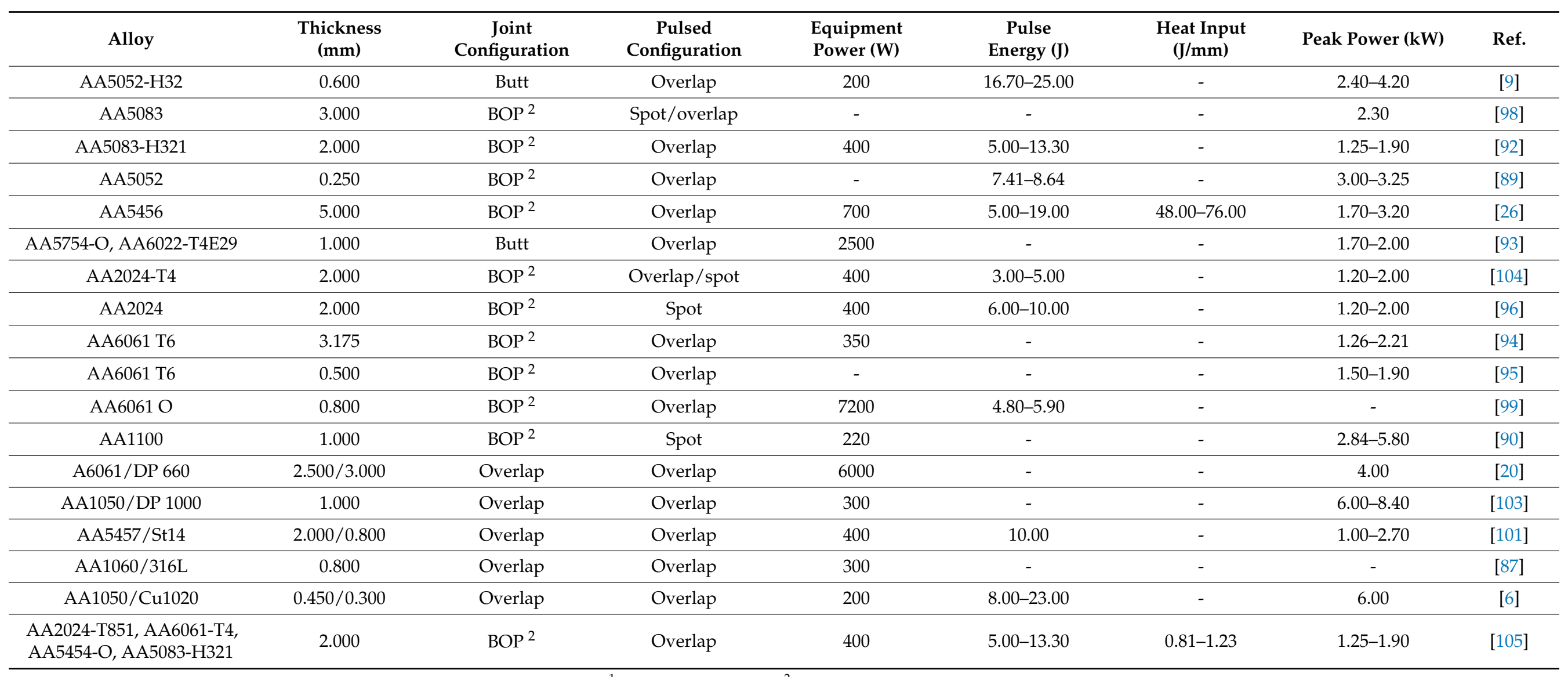

${ }^{1}$ - Argon shielding gas. ${ }^{2}$ - $\mathrm{BOP}$ (bead on plate). 


\subsection{Superalloys}

A superalloy is a denomination used for a group of alloys that contains the main elements: nickel, iron-nickel, or cobalt. These alloys have excellent resistance to high temperature deformation and corrosion [56], where pulsed laser welding can be applied. In the case of Co-based alloys, the pulsed laser was employed on L-605 alloy (UNS R30605) (Figure 16A,B) and the FZ had large austenitic columnar grains with $(\mathrm{W}, \mathrm{Cr})_{7} \mathrm{C}_{3}$ phase original from the BM in the interdendritic regions [106]. The interface revealed large columnar grains with 170-280 $\mu \mathrm{m}$ length, resulting from epitaxial growth, and the HAZ displayed small grains and some amount of the secondary phase. The electron back-scatter diffraction (EBSD) analysis indicated an increase of grains with high angle boundaries (misorientation $>15^{\circ}$ ) with peaks distributed around $80 \%$ in the $\mathrm{HAZ}, 70 \%$ in the FZ, and $50 \%$ in the $\mathrm{BM}$. These microstructural modifications developed a sound joint, with a $1023 \mathrm{MPa}$ tensile strength, which corresponded to $101 \%$ of the BM (Table 9).

Another superalloy from the Fe-Ni-Co system is the Kovar that has significantly low thermal expansion coefficient, being similar to glass. It can be applied as an intermediate material for joining steels with glass [107]. Regarding the application of pulsed laser, some investigations have been developed. Combining Kovar and 304L stainless steel, researchers found that no sound joints were obtained (Figure 16C) [107]. The incomplete mixture of the materials associated with the high solidification rate displayed cracks in the centre of FZ. This region exhibited equiaxed dendrites and columnar dendrites structure of austenitic phase in the fusion interface. A different investigation with Kovar and 420 stainless steel was performed using cylindrical specimens (Figure 16D), and only the welding conditions with low energy involved did not generate cracks in the FZ [108]. The weld metal exhibited austenite microstructure with fine cellular or dendritic morphologies. The joint interface at the Kovar side displayed an epitaxial growth, and in the HAZ no microstructural modification was noted, resulting in austenitic equiaxed grains and some twins. On the AISI 420 side, the FZ presented two different structures: columnar and equiaxed grains. The HAZ revealed precipitation and coarsening carbides in the ferrite grain boundary.

The Hastelloy is a Ni-Mo-Cr alloy widely used in the chemical, aerospace, and nuclear industries. Pulsed laser applied to Hastelloy C-276 generated sound joints with finer microstructures in the FZ divided into three subzones: centre fusion zone (CFZ), transition fusion zone (TFZ), and edge fusion zone (EFZ) (Figure 16E,F) [109]. The CFZ showed mostly fine subgrains due to the rapid solidification. A mixture of the subgrains and columnar dendrite with some fringes was detected in the TFZ, whereas the EFZ had planar and cellular formation. In addition, in the FZ was noticed a tendency of brittle phase transformation. The microhardness indicated the lowest values in the centre of the joint, with an increase of around $40 \mathrm{HV}$ towards the BM. The tensile strength decreased by $10 \%$ compared with that in the BM. The 2D X-ray diffraction analysis performed on the fracture surfaces indicated that there was no brittle phase enrichment. Similar finer microstructures were observed in [110] and [111] (Figure 16G,H); however, brittle precipitates rich in Mo ( $p$ and $\mu$ phases) and micro-segregation were also found at grain boundary [111]. In Hastelloy $X$, the mitigation of cracks was not achieved, even with a reduction of the cooling rate (Figure 16I) [112]. 
In terms of dissimilar welding, the pulsed weld effect on a combination of Hastelloy C-276 and Monel $400 \mathrm{Ni}-\mathrm{Co}$ alloys (typically used for nuclear applications) developed a complete penetration joint (Figure 16J) [113]. The FZ was composed of columnar dendritic grains near the Hastelloy interface and fine dendritic grains in the Monel interface, with austenitic phase $\gamma$, chromium-rich carbide $\left(\mathrm{Cr}_{23} \mathrm{C}_{6}\right)$, and nickel-rich oxide $\left(\mathrm{NiCuO}_{3}\right.$ and $\mathrm{NiFe}_{3} \mathrm{O}_{4}$ ) precipitates. Besides, low Mo segregation and fine microstructure was observed. These characteristics enhanced the joint mechanical strength, resulting in $719 \mathrm{MPa}$ tensile strength (Table 9). When Hastelloy C-276 is combined with 304 stainless steel (304) using a ERNiCrMo-4 welding wire, the dilution level of 304 increased with the laser beam movement towards this material (Figure 16K,L) [114]. At levels from 24.0 to 35.2\%, the volume fraction of precipitated Mo-rich phases ( $p$ and $\mu$ ) was found to be the largest. Nevertheless, values between 73.0 and $85.1 \%$ produced welds insensitive to intergranular corrosion. The same materials were welded with water cooling positioned on the side of C-276, increasing the cooling rate and the temperature gradient (Figure 16M,N) [115]. As a consequence, both the penetration depth and width contracted. However, the high cooling achieved with the water refined the FZ equiaxed grains and diminished the brittle precipitates rich in Mo ( $\mathrm{p}$ and $\mu$ phases), as well as the unmixed zone between the FZ and 304. Another effect was the increase of microhardness in $10 \%$ (287.4 to $317.5 \mathrm{HV})$.

In another application of the technology, the pulsed laser was investigated as a repair welding process in Inconel 617 (Ni-Cr-Co) alloy (Figure 16O) [116]. This process achieved sound bead on plate welds with a cellular structure in the weld meta and no liquation cracks. An increase of up to $40 \mathrm{HV}$ in the FZ microhardness was also observed (Table 9).

Among the studies made with superalloys, some of them demonstrated sound weldments without defects. Positive outcomes were achieved in Inconel using the bead on plate configuration without any cracks. Nevertheless, more investigation may be carried out to ensure the migration of this defect to other welding configurations. The mechanical properties of these joints are shown in Table 9, and additional experimental information can be seen in Table 10 .

Table 9. Selected results of pulsed laser welding apply to superalloys (approximated values).

\begin{tabular}{|c|c|c|c|c|c|}
\hline \multirow{2}{*}{ Alloys } & \multicolumn{3}{|c|}{ Hardness (HV) } & \multirow{2}{*}{$\begin{array}{c}\text { Strength } \\
\text { Performance }\end{array}$} & \multirow{2}{*}{ Ref. } \\
\hline & FZ & HAZ & BM & & \\
\hline UNS R30605 & 325 & 312 & 300 & $\begin{array}{c}1021 \mathrm{MPa}-101 \% \\
\text { Fracture: } \mathrm{BM}\end{array}$ & [106] \\
\hline $\begin{array}{c}\text { Kovar / } \\
\text { 304L }\end{array}$ & $\begin{array}{l}\text { Kovar: } 200 \\
\text { 304L: } 250\end{array}$ & - & $\begin{array}{l}\text { Kovar: } 150 \\
\text { 304L: } 160\end{array}$ & - & [107] \\
\hline $\begin{array}{c}\text { Kovar/ } \\
420\end{array}$ & $\begin{array}{l}\text { Kovar: } 250 \\
\text { 420: } 260\end{array}$ & $\begin{array}{c}\text { Kovar: } 150 \\
420: 375\end{array}$ & $\begin{array}{l}\text { Kovar: } 150 \\
\text { 420: } 230\end{array}$ & - & [108] \\
\hline Hastelloy X & 275 & 255 & 250 & - & [112] \\
\hline Hastelloy C-276 & $260-300$ & - & $240-280$ & $759 \mathrm{MPa}-90 \%$ & [109] \\
\hline $\begin{array}{c}\text { Hastelloy C-276/ } \\
\text { Monel } 400\end{array}$ & - & - & - & $719 \mathrm{MPa}$ & [113] \\
\hline Inconel 617 & 290 & - & 240 & - & [116] \\
\hline
\end{tabular}



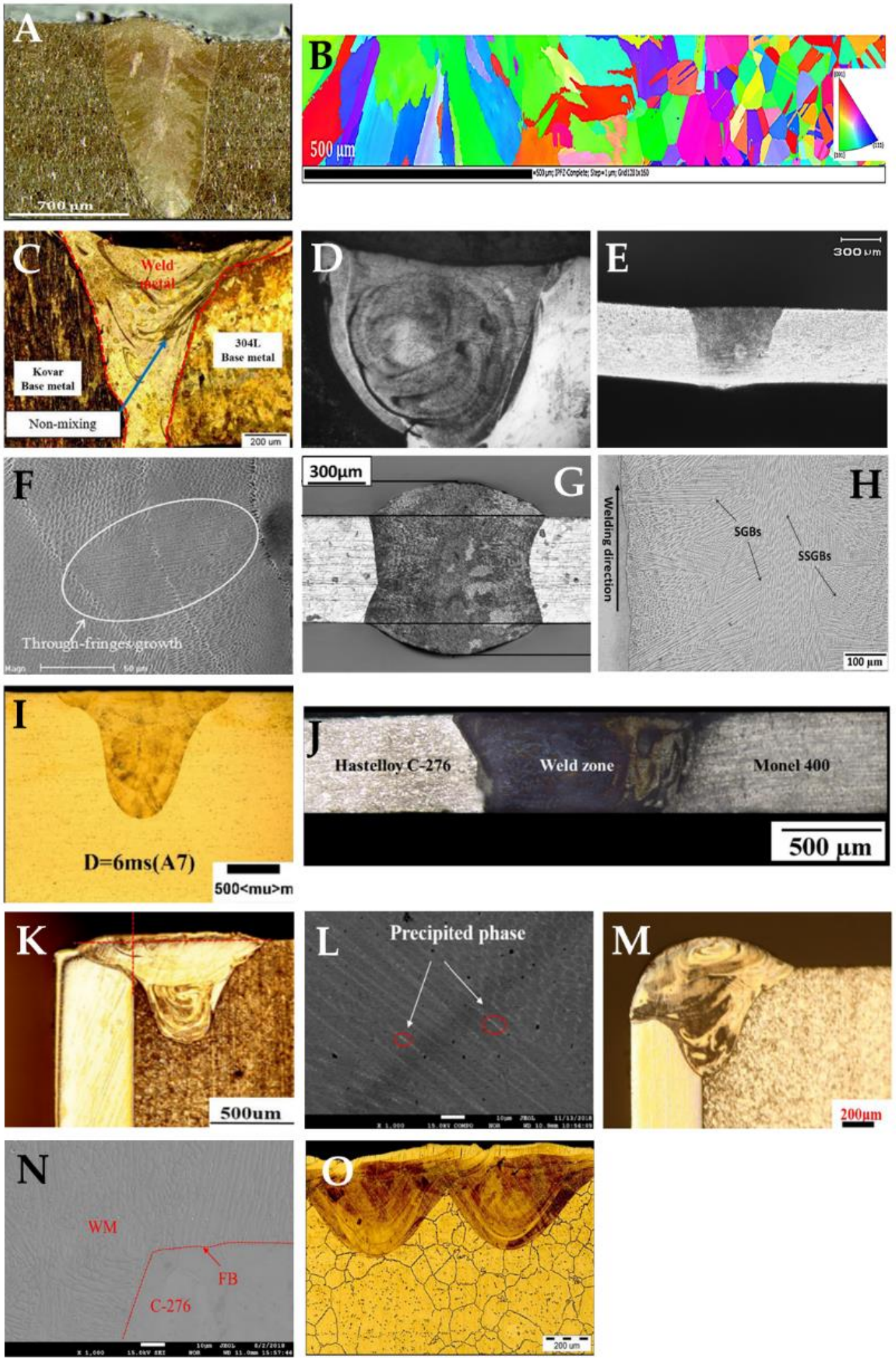

Figure 16. Pulsed laser weldments made of superalloys: L-605 Co-based (A) and its EBSD map (B) [106], Kovar and 304L (C) [107], Kovar and AISI 420 (D) [108], Hastelloy C-276 (E) and its FZ (F) [109], Hastelloy C-276 (G) and its FZ (H) [110,111], Hastelloy X (I) [112], Hastelloy C-276 and Monel 400 (J) [113], Hastelloy C-276 and 304 (K) and its FZ (L) [114], Hastelloy C-276 and 304 welded with water cooling (M) and its FZ (N) [115], and Inconel 617 (O) [116]. 
Table 10. Details of welding conditions applied to superalloy pulsed laser ${ }^{1}$.

\begin{tabular}{|c|c|c|c|c|c|c|c|c|c|}
\hline Alloy & Category & $\begin{array}{l}\text { Thickness } \\
\text { (mm) }\end{array}$ & $\begin{array}{c}\text { Joint } \\
\text { Configuration }\end{array}$ & $\begin{array}{c}\text { Pulsed } \\
\text { Configuration }\end{array}$ & $\begin{array}{l}\text { Equipment } \\
\text { Power (W) }\end{array}$ & $\begin{array}{l}\text { Pulse EW } \\
\text { Energy (J) }\end{array}$ & $\begin{array}{l}\text { Heat Input } \\
(\mathrm{J} / \mathrm{mm})\end{array}$ & $\begin{array}{l}\text { Peak Power } \\
(\mathbf{k W})\end{array}$ & Ref. \\
\hline Kovar/304L & $\mathrm{Fe}-\mathrm{Ni}-\mathrm{Co} /$ stainless steel & 1.0 & Butt & Overlap & 90 & $4.8-5.2$ & $15.0-20.0$ & - & [107] \\
\hline Kovar/420 & $\mathrm{Fe}-\mathrm{Ni}-\mathrm{Co} /$ stainless steel & 2.0 & Butt & Overlap & 100 & - & - & - & [108] \\
\hline Hastelloy X & $\mathrm{Ni}-\mathrm{Mo}-\mathrm{Cr}$ & 0.5 & Butt & Overlap & 550 & $5.0-17.5$ & $18.7-65.6$ & $2.00-2.50$ & [112] \\
\hline Hastelloy C-276 & $\mathrm{Ni}-\mathrm{Mo}-\mathrm{Cr}$ & 0.5 & Butt & Overlap & - & - & - & - & [109] \\
\hline $\begin{array}{c}\text { Hastelloy C-276/ } \\
\text { Monel } 400\end{array}$ & $\mathrm{Ni}-\mathrm{Mo}-\mathrm{Cr} / \mathrm{Ni}-\mathrm{Co}$ & 0.5 & Butt & Overlap & 600 & $8.0-12.0$ & - & - & [113] \\
\hline Inconel 617 & $\mathrm{Ni}-\mathrm{Mo}-\mathrm{Cr}$ & 12.0 & $\mathrm{BOP}^{2}$ & Spot & 100 & - & $15.7-22.3$ & - & [116] \\
\hline L-605 & $\mathrm{Co}-\mathrm{Cr}-\mathrm{W}-\mathrm{Ni}$ & 1.4 & Butt & Overlap & 400 & $12.0-14.0$ & $36.0-93.3$ & $2.00-2.33$ & [106] \\
\hline
\end{tabular}




\section{Outlook and Remarks}

Pulsed laser technology characteristics and their effects on the macro- and microstructure, hardness, and strength performance were studied in the present review. From the outcomes obtained in scientific investigations, one can point out specific characteristics in comparison with other joining processes.

As with any welding technique, the process parameters affect the temperature rates providing modification in metallurgical characteristics and mechanical properties. In pulsed laser welding, the high energy distributed on sharply focused areas achieves high energy density, affecting a small volume of material. Besides the high temperature delivered in few milliseconds, the elevated cooling rate is beneficial for producing narrow HAZ. These features make this process different from conventional fusion welding, in which the high input heat depends on the contact between materials and creates joints with larger HAZ and FZ [72]. Furthermore, even though the pulsed laser is an autogenous process, adding filler and layer materials is an alternative to creating high-resistance transition areas between the base materials. This is important in dissimilar joints when the employment of a third material with a high melting point is needed. In other processes, such as brazing welding, the heat sources deliver gradual input energy in a large volume of material, first affecting materials with low melting point [117]. The fact that the laser beam has high-energy density without contact is another relevant feature. This characteristic is an appealing aspect compared to the friction stir welding process, which requires a nonconsumable tool with specific properties due to the significant levels of wear and heat involved [118-120].

Besides advantages over the established processes, the pulsed laser process has specifics benefits compared to the continuous laser method. The intermittent pulsed laser achieves heating and cooling cycles in every single pulse, making it suitable to apply in superalloys, where the rapid cooling behaviour avoids microsegregation and, consequently, brittle phase transformations [111]. Furthermore, the pulsed profile can be delivered by varying the power over time (pulse shape), controlling the temperature flux and mitigating hot cracking formation in aluminium alloys [94,95,98]. As the bead weld is a sum of multiples pulses overlapped, it thermally affects the previous pulse and can reduce hardness, residual stress, and cooling rate. In high-strength steel alloys, the heat of subsequent pulses modifies the microstructure, refining and tempering the coarse-grained zone in the HAZ, similar to the temper bead welding [121,122]. Furthermore, due to the pulse frequency regime and consequent low average power involved, the high-energy density can be applied using small and relatively low-cost apparatus.

From another perspective, the sequence of laser beams produces weld beads with lower scan velocity than other welding processes. Moreover, the high energy density cycles can evaporate chemical elements with a low melting point, and the cooling rates can generate dispersed micro and nano precipitates in the welding pool. As an accurate method to evaluate phases and precipitates, transmission electron microscopy analysis can support this effectiveness over microstructural and microhardness results. Corrosion assessment also can improve the knowledge associate with the influence of the phases and precipitates in the joint integrity.

All the evaluated studies showed that the pulsed laser welding had been employed in thin plates (up to $3.175 \mathrm{~mm}$ ) because of low penetration depth. Besides this restriction, mechanical tests, such as hardness and tensile and shear strength testing, were used to determine the joint quality. However, the shallow joints limit the application of conventional method impact toughness. Even with the complexity, further investigations of failure mechanism in terms of crack fracture and fatigue should be developed.

\section{Summary}

Significant investigations of pulsed laser welding technology have been increasing in the last 10 years. Outcomes involving a diversity of materials (steel, titanium, aluminium, or superalloys) have shown the versatility of this technique. The present review shows 
that welding process parameters have a remarkable effect on metallurgical and mechanical properties, revealing sound joints made from several alloys in similar and dissimilar configurations. As exhibited, the pulsed laser beam provokes intense material alterations, creating FZ and HAZ with different aspects according to each material and welding conditions. Moreover, the FZ showed a significant microstructural modification associated with a variety of parameters and cooling behaviour. With the same aspect, the HAZ displayed size with un-melting microstructures developed by the rapidly and sharply focused heat input.

Studies on different types of steels indicated that the pulsed process significantly alters the microstructure and mechanical properties. Due to the high cooling, the microstructure underwent intense modifications and, generally, the martensite phase was observed in the FZ. Even though, sound weldments were developed in carbon, stainless, or dual-phase steels. In some cases, the use of post-welding heat treatments was an essential tool to enhance the properties of the stainless steel alloys. Regarding the titanium, the research indicated that the pulsed laser delivers satisfactory properties to the joints made with the most used and investigated Ti6Al4V alloy. Other titanium alloys also demonstrated good weld quality, even with all microstructure modification. In dissimilar combinations, a third material, such as niobium, vanadium, or copper, was employed to reduce the mixture between the materials and avoid intermetallic phases. Concerning aluminium welding, the challenge prevented intrinsic physical effects related to the cracking tendency due to the rapid cooling rates promoted by high thermal conductivity and fast weld process. Nevertheless, some investigations performed with 5000 and 6000 alloys indicated the possibility of applying this welding method to generate sound welds, mitigating the generation of defects through the variation of the welding conditions or application of preheating. When steel and aluminium alloys are combined, brittle intermetallic compounds could be developed; however, the energy variation could re-strain these phases. Moreover, pulsed laser joints of superalloys displayed positive results in some alloys such as Inconel, L-605, Kovar, and Hastelloy.

Overall, these investigations evidence the potential of this technology for industrial applications. Complex and thin materials, ranging from 0.1 to $5 \mathrm{~mm}$, in similar or dissimilar configurations, showed the pulsed laser welding capacity to produce joints with the reduced area affected by the heat input. As highlighted, the majority of the results were positives, displaying joints with high quality.

Author Contributions: Conceptualisation, M.C. and R.E.d.S.; methodology, M.C., C.C. and M.O.-I.; validation, M.O.-I. and C.C.; resources, M.C. and R.E.d.S.; data curation, M.C. and J.M.S.-A.; writingoriginal draft preparation, M.C. and R.E.d.S.; writing-review and editing, M.C. and J.M.S.-A.; supervision, J.M.S.-A. All authors have read and agreed to the published version of the manuscript.

Funding: The present investigation was financially supported by Vicerrectorado de Política Científica y Tecnológica of Universidad de Cádiz (Spain).

Data Availability Statement: Not Applicable.

Acknowledgments: The support from Department of Mechanical Engineering and Industrial Design (TEP 027 research group) of the University of Cadiz is gratefully acknowledged.

Conflicts of Interest: The authors declare no conflict of interest.

\section{References}

1. Steen, W.M. Laser Material Processing; Springer: London, UK, 2003; Volume 113, ISBN 9781849960618.

2. Chatterjee, S.; Sankar, S.; Bharadwaj, V.; Upadhyay, B.N.; Bindra, K.S.; Thomas, J. Parametric appraisal of mechanical and metallurgical behavior of butt welded joints using pulsed Nd:YAG laser on thin sheets of AISI 316. Opt. Laser Technol. 2019, 117, 186-199. [CrossRef]

3. Kumar, N.; Mukherjee, M.; Bandyopadhyay, A. Study on laser welding of austenitic stainless steel by varying incident angle of pulsed laser beam. Opt. Laser Technol. 2017, 94, 296-309. [CrossRef]

4. Dai, J.; Yu, B.; Ruan, Q.; Chu, P.K. Improvement of the laser-welded lap joint of dissimilar mg alloy and cu by incorporation of a Zn interlayer. Materials 2020, 13, 2053. [CrossRef] 
5. Chai, D.; Wu, D.; Ma, G.; Zhou, S.; Jin, Z.; Wu, D. The effects of pulse parameters on weld geometry and microstructure of a pulsed laser welding Ni-base alloy thin sheet with filler wire. Metals 2016, 6, 237. [CrossRef]

6. Lerra, F.; Ascari, A.; Fortunato, A. The influence of laser pulse shape and separation distance on dissimilar welding of $\mathrm{Al}$ and $\mathrm{Cu}$ films. J. Manuf. Process. 2019, 45, 331-339. [CrossRef]

7. Kumar, P.; Nath, S. Comparative analysis of pulsed Nd:YAG laser welding of 304L and 904L stainless steel. Mater. Today Proc. 2020, 33, 5019-5023. [CrossRef]

8. Chang, W.S.; Na, S.J. A study on the prediction of the laser weld shape with varying heat source equations and the thermal distortion of a small structure in micro-joining. J. Mater. Process. Technol. 2002, 120, 208-214. [CrossRef]

9. Abioye, T.E.; Zuhailawati, H.; Aizad, S.; Anasyida, A.S. Geometrical, microstructural and mechanical characterization of pulse laser welded thin sheet 5052-H32 aluminium alloy for aerospace applications. Trans. Nonferr. Met. Soc. China 2019, 29, 667-679. [CrossRef]

10. Sánchez-Amaya, J.M.; Delgado, T.; González-Rovira, L.; Botana, F.J. Laser welding of aluminium alloys 5083 and 6082 under conduction regime. Appl. Surf. Sci. 2009, 255, 9512-9521. [CrossRef]

11. Sun, Q.; Di, H.; Li, J.; Wang, X. Effect of pulse frequency on microstructure and properties of welded joints for dual phase steel by pulsed laser welding. JMADE 2016, 105, 201-211. [CrossRef]

12. Landowski, M.; Świerczyńska, A.; Rogalski, G.; Fydrych, D. Autogenous fiber laser welding of 316L austenitic and 2304 lean duplex stainless steels. Materials 2020, 13, 2930. [CrossRef] [PubMed]

13. Sahul, M.; Tomcíková, E.; Sahul, M.; Pašák, M.; Ludrovcová, B.; Hodúlová, E. Effect of Disk Laser Beam Offset on the Microstructure and Mechanical Properties of Copper-AISI 304 Stainless Steel Dissimilar Metals Joints. Metals 2020, 1294. [CrossRef]

14. Pańcikiewicz, K.; Świerczyńska, A.; Hućko, P.; Tumidajewicz, M. Laser dissimilar welding of AISI 430F and AISI 304 stainless steels. Materials 2020, 13, 4540. [CrossRef]

15. O'Brien, A.; Guzman, C. Welding Handbook- Part 2 Welding Processes, 9th ed.; Elsevier: Amsterdam, The Netherlands, 2007; Volume 3, ISBN 9780871710536.

16. Sánchez-Amaya, J.M.; Delgado, T.; De Damborenea, J.J.; Lopez, V.; Botana, F.J. Laser welding of AA 5083 samples by high power diode laser. Sci. Technol. Weld. Join. 2009, 14, 78-86. [CrossRef]

17. Kumar, N.; Mukherjee, M.; Bandyopadhyay, A. Comparative study of pulsed Nd:YAG laser welding of AISI 304 and AISI 316 stainless steels. Opt. Laser Technol. 2017, 88, 24-39. [CrossRef]

18. Katayama, S. Handbook of Laser Welding Technologies; Woodhead Publishing Limited: Sawston, UK, 2013 ; ISBN 9788578110796.

19. Yaakob, K.I.; Ishak, M.; Quazi, M.M.; Salleh, M.N.M. Optimizing the pulse wave mode low power fibre laser welding parameters of 22Mnb5 boron steel using response surface methodology. Meas. J. Int. Meas. Confed. 2019, 135, 452-466. [CrossRef]

20. Indhu, R.; Divya, S.; Tak, M.; Soundarapandian, S. Microstructure development in Pulsed Laser Welding of Dual Phase Steel to Aluminium Alloy. Procedia Manuf. 2018, 26, 495-502. [CrossRef]

21. Chludzinski, M.; dos Santos, R.E.; Churiaque, C.; Fernández-Vidal, S.R.; Ortega-Iguña, M.; Sánchez-Amaya, J.M. Pulsed laser butt welding of AISI 1005 steel thin plates. Opt. Laser Technol. 2021, 134, 106583. [CrossRef]

22. Quazi, M.M.; Ishak, M.; Fazal, M.A.; Arslan, A.; Rubaiee, S.; Qaban, A.; Aiman, M.H.; Sultan, T.; Ali, M.M.; Manladan, S.M. Current research and development status of dissimilar materials laser welding of titanium and its alloys. Opt. Laser Technol. 2020, 126, 106090. [CrossRef]

23. Katayama, S. Understanding and improving process control in pulsed and continuous wave laser welding. In Advances in Laser Materials Processing; Elsevier Ltd.: Amsterdam, The Netherlands, 2018; pp. 181-210. ISBN 9781845694746.

24. Tzeng, Y.F. Process characterization of pulsed Nd:YAG laser seam welding. Int. J. Adv. Manuf. Technol. 2000, 16, 10-18. [CrossRef]

25. Tzeng, Y.F. Parametric analysis of the pulsed Nd:YAG laser seam-welding process. J. Mater. Process. Technol. 2000, 102, 40-47. [CrossRef]

26. Hekmatjou, H.; Naffakh-Moosavy, H. Hot cracking in pulsed Nd: YAG laser welding of AA5456. Opt. Laser Technol. 2018, 103, 22-32. [CrossRef]

27. Tur, A.; Cordovilla, F.; García-Beltrán, Á.; Ocaña, J.L. Minimization of the thermal material effects on pulsed dynamic laser welding. J. Mater. Process. Technol. 2017, 246, 13-21. [CrossRef]

28. Desai, R.S.; Bag, S. Influence of displacement constraints in thermomechanical analysis of laser micro-spot welding process. J. Manuf. Process. 2014, 16, 264-275. [CrossRef]

29. Chaturvedi, M.C. Welding and Joining of Aerospace Materials; Woodhead Publishing Limited: Sawston, UK, 2012; ISBN 978-0-85709-523-7.

30. Olsen, F.O. Hybrid Laser arc Welding, 2009th ed.; Woodhead Publishing Limited: Cambridge, UK, $2009 ;$ ISBN 9781845691301.

31. Churiaque, C.; Amaya-Vazquez, M.R.; Botana, F.J.; Sánchez-Amaya, J.M. FEM Simulation and Experimental Validation of LBW Under Conduction Regime of Ti6Al4V Alloy. J. Mater. Eng. Perform. 2016, 25, 3260-3269. [CrossRef]

32. Assuncao, E.; Williams, S. Comparison of continuous wave and pulsed wave laser welding effects. Opt. Lasers Eng. 2013, 51, 674-680. [CrossRef]

33. Assuncao, E.; Williams, S.; Yapp, D. Interaction time and beam diameter effects on the conduction mode limit. Opt. Lasers Eng. 2012, 50, 823-828. [CrossRef]

34. Torkamany, M.J.; Malek Ghaini, F.; Poursalehi, R.; Kaplan, A.F.H. Combination of laser keyhole and conduction welding: Dissimilar laser welding of niobium and Ti-6Al-4V. Opt. Lasers Eng. 2016, 79, 9-15. [CrossRef]

35. Sibillano, T.; Ancona, A.; Berardi, V.; Schingaro, E.; Basile, G.; Lugarà, P.M. Optical detection of conduction/keyhole mode transition in laser welding. J. Mater. Process. Technol. 2007, 191, 364-367. [CrossRef] 
36. Sánchez-Amaya, J.; Pasang, T.; Amaya-Vazquez, M.; Lopez-Castro, J.; Churiaque, C.; Tao, Y.; Botana Pedemonte, F. Microstructure and Mechanical Properties of Ti5553 Butt Welds Performed by LBW under Conduction Regime. Metals 2017, 7, 269. [CrossRef]

37. Chen, H.C.; Bi, G.; Lee, B.Y.; Cheng, C.K. Laser welding of CP Ti to stainless steel with different temporal pulse shapes. J. Mater. Process. Technol. 2016, 231, 58-65. [CrossRef]

38. Ventrella, A.; Roberto, J.; Rossi, W. De Pulsed Nd:YAG laser seam welding of AISI 316L stainless steel thin foils. J. Mater. Process. Tech. 2010, 210, 1838-1843. [CrossRef]

39. Mojaver, R.; Mojtahedi, F.; Shahverdi, H.R.; Torkamany, M.J. Study on feasibility of producing an amorphous surface layer of Fe 49 Cr 18 Mo 7 B 16 C 4 Nb 3 by pulsed Nd:YAG laser surface melting. Appl. Surf. Sci. 2013, 264, 176-183. [CrossRef]

40. Mostaan, H.; Shamanian, M.; Hasani, S.; Safari, M.; Szpunar, J.A. Nd:YAG laser micro-welding of ultra-thin FeCo-V magnetic alloy: Optimization of weld strength. Trans. Nonferr. Met. Soc. China 2017, 27, 1735-1746. [CrossRef]

41. Gao, X.L.; Liu, J.; Zhang, L.J.; Zhang, J.X. Effect of the overlapping factor on the microstructure and mechanical properties of pulsed Nd:YAG laser welded Ti6Al4V sheets. Mater. Charact. 2014, 93, 136-149. [CrossRef]

42. Torabi, A.; Kolahan, F. Optimizing pulsed Nd: YAG laser beam welding process parameters to attain maximum ultimate tensile strength for thin AISI316L sheet using response surface methodology and simulated annealing algorithm. Opt. Laser Technol. 2018, 103, 300-310. [CrossRef]

43. John, C. Lippold Welding Metallurgy and Weldability; John Wiley \& Sons, Inc.: Hoboken, NJ, USA, $2015 ;$ ISBN 9789896540821.

44. Linnert, G.E.; Kou, S.; Zhou, J.; Tsai, H.L.; Wang, P.C. Welding Metallurgy; Woodhead Publishing Limited: Sawston, UK, 2003; Volume 1, ISBN 3175723993.

45. Gnanasekaran, S.; Senthil Kumar, S.; Venugopal, N.; Upadhyaya, M.; Manjunath, T.C.; Chelladurai, S.J.S.; Padmanaban, G. Effect of laser power on microstructure and tensile properties of pulsed Nd:YAG laser beam welded AISI 301 austenitic stainless steel joints. Mater. Today Proc. 2020, 37, 934-939. [CrossRef]

46. Zhao, X.; Shi, Z.; Deng, C.; Liu, Y.; Li, X. The effect of laser offset welding on microstructure and mechanical properties of 301L to TA2 with and without $\mathrm{Cu}$ intermediate layer. Metals 2020, 10, 1138. [CrossRef]

47. Mohammed, G.R.; Ishak, M.; Ahmad, S.N.A.S.; Abdulhadi, H.A. Fiber laser welding of dissimilar 2205/304 stainless steel plates. Metals 2017, 7, 546. [CrossRef]

48. Li, J.; Cai, Y.; Yan, F.; Wang, C.; Zhu, Z.; Hu, C. Porosity and liquation cracking of dissimilar Nd:YAG laser welding of SUS304 stainless steel to T2 copper. Opt. Laser Technol. 2020, 122, 105881. [CrossRef]

49. He, H.; Forouzan, F.; Volpp, J.; Robertson, S.M.; Vuorinen, E. Microstructure and mechanical properties of laser-welded DP steels used in the automotive industry. Materials 2021, 14, 456. [CrossRef] [PubMed]

50. Trinh, L.N.; Lee, D. The characteristics of laser welding of a thin aluminum tab and steel battery case for lithium-ion battery. Metals 2020, 10, 842. [CrossRef]

51. Quazi, M.M.; Ishak, M.; Fazal, M.A.; Arslan, A.; Rubaiee, S.; Aiman, M.H.; Qaban, A.; Yusof, F.; Sultan, T.; Ali, M.M.; et al. A comprehensive assessment of laser welding of biomedical devices and implant materials: Recent research, development and applications. Crit. Rev. Solid State Mater. Sci. 2020, 46, 109-151. [CrossRef]

52. Kumar, P.; Sinha, A.N. Microstructure and mechanical properties of pulsed Nd:YAG laser welding of st37 carbon steel. Procedia Comput. Sci. 2018, 133, 733-739. [CrossRef]

53. Malek Ghaini, F.; Hamedi, M.J.; Torkamany, M.J.; Sabbaghzadeh, J. Weld metal microstructural characteristics in pulsed Nd: YAG laser welding. Scr. Mater. 2007, 56, 955-958. [CrossRef]

54. Fayazi Khanigi, A.; Farnia, A.; Ardestani, M.; Torkamany, M.J. Microstructure and mechanical properties of low power pulsed Nd:YAG laser welded S700MC steel. Sādhanā 2020, 45, 1-13. [CrossRef]

55. Vahiddastjerdi, H.; Rezaeian, A.; Toroghinejad, M.R.; Dini, G.; Ghassemali, E. Optimizing pulsed Nd:YAG laser welding of high-Mn TWIP steel using response surface methodology technique. Opt. Laser Technol. 2019, 120, 105721. [CrossRef]

56. Xue, X.; Pereira, A.B.; Amorim, J.; Liao, J. Effects of pulsed Nd: YAG laser welding parameters on penetration and microstructure characterization of a DP1000 steel butt joint. Metals 2017, 7, 292. [CrossRef]

57. Fernandes, F.A.O.; Oliveira, D.F.; Pereira, A.B. Optimal parameters for laser welding of advanced high-strength steels used in the automotive industry. Procedia Manuf. 2017, 13, 219-226. [CrossRef]

58. Tuncel, O.; Aydin, H. A comparison of tensile properties of single-sided and double-sided laser welded DP600 steel sheets. Mater. Sci. 2020, 26, 173-178. [CrossRef]

59. McGuire, M. Stainless Steels for Design Engineers; ASM International: Materials Park, OH, USA, 2008 ; ISBN 9780871707178.

60. Baghjari, S.H.; Akbari Mousavi, S.A.A. Effects of pulsed Nd: YAG laser welding parameters and subsequent post-weld heat treatment on microstructure and hardness of AISI 420 stainless steel. Mater. Des. 2013, 43, 1-9. [CrossRef]

61. Saravanan, S.; Sivagurumanikandan, N.; Raghukandan, K. Effect of process parameters in microstructural and mechanical properties of Nd: YAG laser welded super duplex stainless steel. Mater. Today Proc. 2020, 1-6.

62. Saravanan, S.; Raghukandan, K.; Sivagurumanikandan, N. Pulsed Nd: YAG laser welding and subsequent post-weld heat treatment on super duplex stainless steel. J. Manuf. Process. 2017, 25, 284-289. [CrossRef]

63. Mousavi, S.A.A.A.; Sufizadeh, A.R. Metallurgical investigations of pulsed Nd:YAG laser welding of AISI 321 and AISI 630 stainless steels. Mater. Des. 2009, 30, 3150-3157. [CrossRef]

64. Balajaddeh, M.; Naffakh-Moosavy, H. Pulsed Nd:YAG laser welding of 17-4 PH stainless steel: Microstructure, mechanical properties, and weldability investigation. Opt. Laser Technol. 2019, 119, 105651. [CrossRef] 
65. Torkamany, M.J.; Sabbaghzadeh, J.; Hamedi, M.J. Effect of laser welding mode on the microstructure and mechanical performance of dissimilar laser spot welds between low carbon and austenitic stainless steels. Mater. Des. 2012, 34, 666-672. [CrossRef]

66. Nguyen, Q.; Azadkhou, A.; Akbari, M.; Panjehpour, A.; Karimipour, A. Experimental investigation of temperature field and fusion zone microstructure in dissimilar pulsed laser welding of austenitic stainless steel and copper. J. Manuf. Process. 2020, 56, 206-215. [CrossRef]

67. Ascari, A.; Fortunato, A. Nanosecond pulsed laser welding of high carbon steels. Opt. Laser Technol. 2014, 56, 25-34. [CrossRef]

68. Amaya-Vazquez, M.R.; Sánchez-Amaya, J.M.; Boukha, Z.; Botana, F.J. Microstructure, microhardness and corrosion resistance of remelted TiG2 and Ti6Al4V by a high power diode laser. Corros. Sci. 2012, 56, 36-48. [CrossRef]

69. Akman, E.; Demir, A.; Canel, T.; Sinmazçelik, T. Laser welding of Ti6Al4V titanium alloys. J. Mater. Process. Technol. 2009, 209, 3705-3713. [CrossRef]

70. Akbari, M.; Saedodin, S.; Toghraie, D. Experimental and numerical investigation of temperature distribution and melt pool geometry during pulsed laser welding of Ti6Al4V alloy. Opt. Laser Technol. 2014, 59, 52-59. [CrossRef]

71. Sánchez-Amaya, J.M.; Amaya-Vázquez, M.R.; González-Rovira, L.; Botana-Galvin, M.; Botana, F.J. Influence of surface pretreatments on laser welding of Ti6Al4V alloy. J. Mater. Eng. Perform. 2014, 23, 1568-1575. [CrossRef]

72. Gao, X.; Zhang, L.; Liu, J.; Zhang, J. A comparative study of pulsed Nd:YAG laser welding and TIG welding of thin Ti6Al4V titanium alloy plate. Mater. Sci. Eng. A 2013, 559, 14-21. [CrossRef]

73. Kumar, B.; Bag, S.; Paul, C.P.; Das, C.R.; Ravikumar, R.; Bindra, K.S. Influence of the mode of laser welding parameters on microstructural morphology in thin sheet Ti6Al4V alloy. Opt. Laser Technol. 2020, 131, 106456. [CrossRef]

74. Sarre, B.; Flouriot, S.; Geandier, G.; Panicaud, B.; Rancourt, V. De Mechanical behavior and fracture mechanisms of titanium alloy welded joints made by pulsed laser beam welding. Procedia Struct. Integr. 2016, 2, 3569-3576. [CrossRef]

75. Junaid, M.; Baig, M.N.; Shamir, M.; Khan, F.N.; Rehman, K.; Haider, J. A comparative study of pulsed laser and pulsed TIG welding of Ti-5Al-2.5Sn titanium alloy sheet. J. Mater. Process. Technol. 2017, 242, 24-38. [CrossRef]

76. Fang, X.; Zhang, J. Effects of microstructure and concavity on damage behavior of laser beam welded Ti-2Al-1.5Mn titanium alloy joints. Int. J. Adv. Manuf. Technol. 2015, 79, 1557-1568. [CrossRef]

77. Wei-huai, G.; Yu-hua, C.; Li-ming, K.E. Microstructure and properties of laser micro welded joint of TiNi shape memory alloy. Trans. Nonferr. Met. Soc. China 2011, 21, 2044-2048.

78. Wang, L.; Sun, D.; Li, H.; Gu, X.; Shen, C. Microstructures and Mechanical Properties of a Laser-Welded Joint of Ti3Al-Nb Alloy Using Pure Nb Filler Metal. Metals 2018, 8, 785. [CrossRef]

79. Li, D.; Hu, S.; Shen, J.; Zhang, H.; Bu, X. Microstructure and Mechanical Properties of Laser-Welded Joints of Ti-22Al-25Nb/TA15 Dissimilar Titanium Alloys. J. Mater. Eng. Perform. 2016, 25, 1880-1888. [CrossRef]

80. Chen, Y.; Mao, Y.; Lu, W.; He, P. Investigation of welding crack in micro laser welded NiTiNb shape memory alloy and Ti6Al4V alloy dissimilar metals joints. Opt. Laser Technol. 2017, 91, 197-202. [CrossRef]

81. Xue, X.; Pereira, A.; Vincze, G.; Wu, X.; Liao, J. Interfacial characteristics of dissimilar Ti6AL4V/aa6060 lap joint by pulsed nd:YAG laser welding. Metals 2019, 9, 71. [CrossRef]

82. Torkamany, M.J.; Ghaini, F.M.; Poursalehi, R. Dissimilar pulsed Nd:YAG laser welding of pure niobium to Ti-6Al-4V. Mater. Des. 2014, 53, 915-920. [CrossRef]

83. Torkamany, M.J.; Ghaini, F.M.; Poursalehi, R. An insight to the mechanism of weld penetration in dissimilar pulsed laser welding of niobium and Ti-6Al-4V. Opt. Laser Technol. 2016, 79, 100-107. [CrossRef]

84. Zhang, Y.; Zhou, J.; Sun, D.; Li, H. Two pass laser welding of TC4 Titanium alloy to 301L stainless steel via pure v interlayer. J. Mater. Res. Technol. 2020, 9, 1400-1404. [CrossRef]

85. Zhang, Y.; Chen, Y.; Zhou, J.; Sun, D.; Gu, X. Forming mechanism and mechanical property of pulsed laser welded Ti alloy and stainless steel joint using copper as interlayer. J. Mater. Res. Technol. 2020, 9, 1425-1433. [CrossRef]

86. Gursel, A. Crack risk in Nd: YAG laser welding of Ti-6Al-4V alloy. Mater. Lett. 2017, 197, 233-235. [CrossRef]

87. Yang, J.; Li, Y.; Zhang, H. Microstructure and mechanical properties of pulsed laser welded Al/steel dissimilar joint. Trans. Nonferr. Met. Soc. China 2016, 26, 994-1002. [CrossRef]

88. Costanza, G.; Tata, M.E. Mechanical behavior of Nd:YAG laser welded aluminum alloys. Procedia Struct. Integr. 2020, 28, 132-138. [CrossRef]

89. Chua, S.F.; Chen, H.; Bi, G. Influence of pulse energy density in micro laser weld of crack sensitive Al alloy sheets. J. Manuf. Process. 2019, 38, 1-8. [CrossRef]

90. Hajavifard, R.; Motahari, M.; Özden, H.; Miyanaji, H.; Kafashi, S. The Effects of Pulse Shaping Variation in Laser Spot- Welding of Aluminum. Procedia Manuf. 2016, 5, 232-247. [CrossRef]

91. Sánchez-Amaya, J.M.; Boukha, Z.; Amaya-Vázquez, M.R.; Botana, F.J. Weldability of aluminum alloys with high-power diode laser. Weld. J. 2012, 91, 155-161.

92. Beiranvand, Z.M.; Ghaini, F.M.; Moosavy, H.N.; Sheikhi, M.; Torkamany, M.J. Solidification cracking susceptibility in pulsed laser welding of Al-Mg alloys. Materialia 2019, 7, 100417. [CrossRef]

93. Kuo, T.Y.; Lin, H.C. Effects of pulse level of Nd-YAG laser on tensile properties and formability of laser weldments in automotive aluminum alloys. Mater. Sci. Eng. A 2006, 416, 281-289. [CrossRef]

94. Zhang, J.; Weckman, D.C.; Zhou, Y. Effects of temporal pulse shaping on cracking susceptibility of 6061-T6 aluminum Nd:YAG laser welds. Weld. J. 2008, 87, 18-30. 
95. Von Witzendorff, P.; Kaierle, S.; Suttmann, O.; Overmeyer, L. Using pulse shaping to control temporal strain development and solidification cracking in pulsed laser welding of 6082 aluminum alloys. J. Mater. Process. Technol. 2015, 225, 162-169. [CrossRef]

96. Sheikhi, M.; Ghaini, F.M.; Assadi, H. Prediction of solidification cracking in pulsed laser welding of 2024 aluminum alloy. Acta Mater. 2015, 82, 491-502. [CrossRef]

97. Loginova, I.; Khalil, A.; Pozdniakov, A.; Solonin, A.; Zolotorevskiy, V. Effect of pulse laser welding parameters and filler metal on microstructure and mechanical properties of Al-4.7Mg-0.32Mn-0.21Sc-0.1Zr alloy. Metals 2017, 7, 564. [CrossRef]

98. Jia, Z.; Zhang, P.; Yu, Z.; Shi, H.; Liu, H.; Wu, D.; Ye, X.; Wang, F.; Tian, Y. Effect of pulse shaping on solidification process and crack in 5083 aluminum alloy by pulsed laser welding. Opt. Laser Technol. 2021, 134, 106608. [CrossRef]

99. Ebrahimzadeh, H.; Farhangi, H.; Akbari Mousavi, S.A.A. Effect of local compressive residual stresses on pulsed Nd:YAG laser welding of Al-Mg-Si alloys. Mater. Res. Express 2019, 6, 036521. [CrossRef]

100. Meco, S.; Pardal, G.; Ganguly, S.; Miranda, R.M.; Quintino, L.; Williams, S. Overlap conduction laser welding of aluminium to steel. Int. J. Adv. Manuf. Technol. 2013, 67, 647-654. [CrossRef]

101. Torkamany, M.J.; Tahamtan, S.; Sabbaghzadeh, J. Dissimilar welding of carbon steel to 5754 aluminum alloy by Nd:YAG pulsed laser. Mater. Des. 2010, 31, 458-465. [CrossRef]

102. Meco, S.; Pardal, G.; Ganguly, S.; Williams, S.; McPherson, N. Application of laser in seam welding of dissimilar steel to aluminium joints for thick structural components. Opt. Lasers Eng. 2015, 67, 22-30. [CrossRef]

103. Pereira, A.B.; Cabrinha, A.; Rocha, F.; Marques, P.; Fernandes, F.A.O.; Alves de Sousa, R.J. Dissimilar metals laser welding between DP1000 steel and aluminum alloy 1050. Metals 2019, 9, 102. [CrossRef]

104. Sheikhi, M.; Ghaini, F.M.; Torkamany, M.J.; Sabbaghzadeh, J. Characterisation of solidification cracking in pulsed Nd:YAG laser welding of 2024 aluminium alloy. Sci. Technol. Weld. Join. 2009, 14, 161-165. [CrossRef]

105. Beiranvand, Z.M.; Ghaini, F.M.; Moosavy, H.N.; Sheikhi, M.; Torkamany, M.J.; Moradi, M. The relation between magnesium evaporation and laser absorption and weld penetration in pulsed laser welding of aluminum alloys: Experimental and numerical investigations. Opt. Laser Technol. 2020, 128, 106170. [CrossRef]

106. Shamanian, M.; Valehi, M.; Kangazian, J.; Szpunar, J.A. EBSD characterization of the L-605 Co-based alloy welds processed by pulsed Nd:YAG laser welding. Opt. Laser Technol. 2020, 128, 106256. [CrossRef]

107. Akhiri Ardakania, H.; Naffakh-Moosav, H. The effect of pulsed Nd:YAG laser welding parameters on defects of Kovar to AISI 304L dissimilar joint. Opt. Laser Technol. 2019, 118, 62-68. [CrossRef]

108. Baghjari, S.H.; AkbariMousavi, S.A.A. Experimental investigation on dissimilar pulsed Nd: YAG laser welding of AISI 420 stainless steel to kovar alloy. Mater. Des. 2014, 57, 128-134. [CrossRef]

109. Ma, G.; Wu, D.; Niu, F.; Zou, H. Microstructure evolution and mechanical property of pulsed laser welded Ni-based superalloy. Opt. Lasers Eng. 2015, 72, 39-46. [CrossRef]

110. Cheng, B.; Wu, D.; Liu, J.; Cui, Q.; Zhou, S.; Ma, G.; Niu, F.; Chai, D.; Ma, G.; Zhou, S.; et al. Cavitation erosion behavior of Hastelloy ${ }^{\mathrm{TM}}$ C-276 weld by laser welding. J. Manuf. Process. 2019, 72, $226-234$.

111. Ma, G.; Wu, D.; Guo, D. Segregation characteristics of pulsed laser butt welding of hastelloy C-276. Metall. Mater. Trans. A Phys. Metall. Mater. Sci. 2011, 42, 3853-3857.

112. Pakniat, M.; Ghaini, F.M.; Torkamany, M.J. Hot cracking in laser welding of Hastelloy X with pulsed Nd:YAG and continuous wave fiber lasers. Mater. Des. 2016, 106, 177-183.

113. Kumar, G.S.; Raghukandan, K.; Saravanan, S.; Sivagurumanikandan, N. Optimization of parameters to attain higher tensile strength in pulsed Nd:YAG laser welded Hastelloy C-276-Monel 400 sheets. Infrared Phys. Technol. 2019, 100, 1-10. [CrossRef]

114. Cheng, B.; Wu, D.; Liu, J.; Cui, Q.; Zhou, S.; Ma, G.; Niu, F. Adjust dilution level to suppress the precipitated phase by dilution level model of dissimilar metal laser welding with filler wire. Opt. Laser Technol. 2020, 125, 106025. [CrossRef]

115. Wu, D.; Cheng, B.; Liu, J.; Liu, D.; Ma, G.; Yao, Z. Water cooling assisted laser dissimilar welding with filler wire of nickel-based alloy/austenitic stainless steel. J. Manuf. Process. 2019, 45, 652-660. [CrossRef]

116. Taheri, N.; Naffakh-Moosavy, H.; Malek Ghaini, F. A new procedure for refurbishment of power plant Superalloy 617 by pulsed Nd: YAG laser process. Opt. Laser Technol. 2017, 91, 71-79. [CrossRef]

117. Venkatesu, S.; Gangaraju, M.; Bhaskar, S.; Vardhana Naidu, B.V. A Study of Laser Beam Welding, Gas Tungsten Arc Welding and High Temperature Brazing Processes on Micro hardness and Tensile Strength of AISI Type 316 Stainless Steel. Procedia Comput. Sci. 2018, 133, 10-18. [CrossRef]

118. Balachandar, K.; Jegadeeshwaran, R.; Gandhikumar, D. Condition monitoring of FSW tool using vibration analysis-A machine learning approach. Mater. Today Proc. 2019, 27, 2970-2974. [CrossRef]

119. Nandan, R.; DebRoy, T.; Bhadeshia, H.K.D.H. Recent advances in friction-stir welding - Process, weldment structure and properties. Prog. Mater. Sci. 2008, 53, 980-1023. [CrossRef]

120. Wang, J.; Su, J.; Mishra, R.S.; Xu, R.; Baumann, J.A. Tool wear mechanisms in friction stir welding of Ti-6Al-4V alloy. Wear 2014, 321, 25-32. [CrossRef]

121. Dobrotă, D. Optimizing the shape of welded constructions made through the technique "temper bead welding". Metals 2020, 10, 1655. [CrossRef]

122. Tomków, J.; Rogalski, G.; Fydrych, D.; Labanowski, J. Advantages of the application of the temper bead welding technique during wet welding. Materials 2019, 16, 915. [CrossRef] [PubMed] 